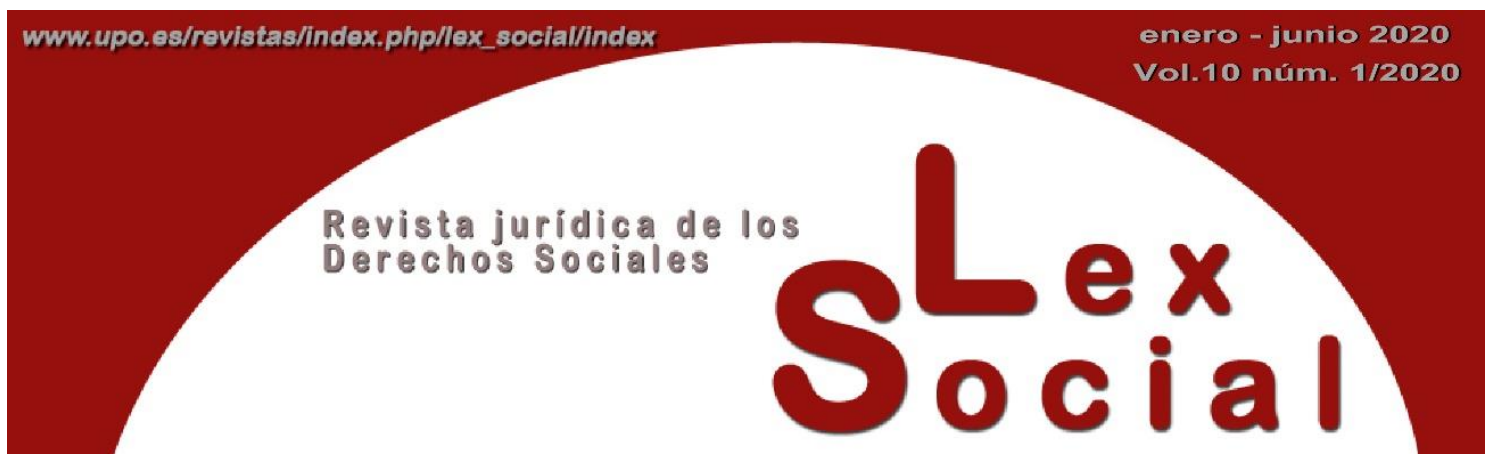

\title{
LA GARANTÍA DEL COMITÉ EUROPEO DE DERECHOS SOCIALES: UN COMPROMISO REAL CON LOS DERECHOS SOCIALES
}

\section{THE GUARANTEE OF THE EUROPEAN COMMITTEE OF SOCIAL RIGHTS: A REAL COMMITMENT TO SOCIAL RIGHTS}

\author{
MÓNICA ARENAS RAMIRO \\ Profesora Contratada Doctora de Derecho Constitucional \\ Universidad de Alcalá
}

Artículo recibido el 4 de noviembre de 2019

Artículo aceptado el 14 de noviembre de 2019

\section{RESUMEN}

La eficacia de los derechos está vinculada a su reconocimiento y, especialmente, a sus mecanismos de protección. El instrumento fundamental y específico, por excelencia, de reconocimiento y protección de los derechos sociales es la Carta Social Europea (CSE). La Carta cuenta con el Comité Europeo de Derechos Sociales (CEDS) como garante de los derechos en ella reconocidos. Su jurisprudencia debería ser un referente para los órganos nacionales y sus decisiones y mecanismos de protección deberían asumirse como vinculantes. Un compromiso real con los derechos sociales pasa por ratificar la Carta y todas las vías de protección ante el CEDS, como las reclamaciones colectivas. En febrero de 2019 el Gobierno español acordó ratificar el texto revisado de la CSE, dejando fuera la posibilidad de las reclamaciones colectivas. La disolución de las Cortes en marzo de 2019 dejó en suspenso tanto la ratificación como la posibilidad de que en sede parlamentaria se hubiera apostado por asumir todas las vías de protección de los derechos sociales, dotándoles de visibilidad, exigibilidad y eficacia, haciendo real la forma social de nuestro Estado. A falta de una vía jurisdiccional 
coherente a nivel nacional respecto de la eficacia directa de la CSE, el Defensor del Pueblo se vislumbra como el asidero al que agarrarse para hacer valer los derechos sociales reconocidos en nuestro texto constitucional.

Palabras Clave: Carta Social Europea (CSE), Comité Europeo de Derechos Sociales (CEDS), defensor del pueblo, derechos sociales, dignidad, justiciabilidad.

\begin{abstract}
The effectiveness of rights is linked to their recognition and, in particular, to their protection mechanisms. The fundamental and specific instrument par excellence for the recognition and protection of social rights is the European Social Charter (ESC). The Charter relies on the European Committee of Social Rights (ECSR) as the guarantor of the rights it recognises. Its jurisprudence should be a reference for national bodies and its decisions and protection mechanisms should be assumed as binding. A real commitment to social rights is to ratify the Charter and all means of protection before the ECSR, such as collective claims. In February 2019 the Spanish Government agreed to ratify the revised text of the ECS, leaving out the possibility of collective claims. The dissolution of the Cortes in March 2019 put both the ratification and the possibility that the parliamentary seat had bet on assuming all the ways of protecting social rights, giving them visibility, enforceability and efficiency, making real the social form of our State. In the absence of a coherent jurisdictional route at the national level with respect to the direct effectiveness of the ESC, the Ombudsman is seen as the handhold to which to cling in order to assert the social rights recognized in our constitutional text.
\end{abstract}

KEYwORDS: European Social Charter (ESC), European Committee of Social Rights (ECSR), Ombudsman, social rights, dignity, justiciability.

SUMARIO

\title{
I. INTRODUCCIÓN
}

II. LA CARTA SOCIAL EUROPEA Y LOS DERECHOS SOCIALES

III. EL PAPEL DEL COMITÉ EUROPEO DE DERECHOS SOCIALES

IV. LA ASIGNATURA PENDIENTE DE ESPAÑA EN DERECHOS SOCIALES: LA VINCULACIÓN REAL AL COMITÉ EUROPEO DE DERECHOS SOCIALES

1. La necesaria ratificación efectiva de la Carta Social Europea y sus Protocolos

2. Los Tribunales nacionales

3. El Defensor del Pueblo 


\section{A MODO DE CONCLUSIÓN}

\section{BIBLIOGRAFÍA}

\section{INTRODUCCIÓN}

Hablar de derechos sociales significa hablar de justicia social y de dignidad personal. La protección de la dignidad personal, y la eliminación de cualquier forma de discriminación, pasa por proteger a los grupos más vulnerables de la explotación, la esclavitud y la mercantilización. ${ }^{1}$ Para que no existan grupos vulnerables se deben aprobar políticas sociales activas que, además de reconocer derechos y prestaciones sociales, garantizándolos como derechos universales e indivisibles, ${ }^{2}$ fijen entre sus objetivos la igualdad de género y el empoderamiento de la mujer, que eviten caer en una situación de vulnerabilidad. Los derechos sociales tienen como fin último garantizar unas condiciones de vida dignas iguales para todos los ciudadanos. ${ }^{3}$

Por otro lado, no es menos cierto, que los derechos sociales nacen vinculados a la idea de Estado de bienestar y que, históricamente -lo que marca la problemática de su justiciabilidad-, se les ha hecho depender de los recursos de los que dispone el Estado,

\footnotetext{
${ }^{1}$ Situaciones injustas y discriminatorias se dirigen, normalmente, a los grupos y sectores más vulnerables, a grupos discriminados, minoritarios o excluidos socialmente y, también, a las mujeres en mayor proporción que a los hombres. Aquí el género se convierte en un importante factor a tener en cuenta pues, en determinadas situaciones, especialmente, las relacionadas con los derechos laborales, incrementan la posibilidad de ser víctima de prácticas como la explotación sexual forzosa, y el trabajo doméstico forzoso o servidumbre doméstica, que en muchos casos va a suponer un tipo de discriminación múltiple en tanto que tiene en cuenta no sólo el género, sino factores como la nacionalidad. Se estima que el $22 \%$ del trabajo forzoso se produce en la industria del sexo, lo que se traduce en que 4 millones y medio de personas están sometidas a explotación sexual. Sobre estas cifras, vid. OIT, Profits and Poverty: The Economics of Forced Labour, Ginebra, 2014, pp. 7, 11, 25, 29-36; e Informe de la Comisión sobre Los progresos realizados en la lucha contra la trata de seres humanos, 19 de mayo de 2016 (COM (2016) 267 final). Sobre estas cuestiones, vid., también, LOUSADA AROCHENA, J.F., "Normativa internacional contra la explotación humana y laboral en el trabajo doméstico: la ONU y la OIT", Lan Harremanak, n 39, 2018, pp. 164-165; LOPEZ AHUMADA, J.E., "Trabajo decente y globalización en Latinoamérica: una alternativa a la desigualdad laboral y social", Documentos de Trabajo IELAT, $\mathrm{n}^{\circ}$ 98, 2017, pp. 17-18; y FERNÁNDEZ BURGUEÑO, B., "El trabajo forzado, la servidumbre y la esclavitud en Europa atendiendo a los sectores productivos: análisis crítico del alcance de la jurisprudencia del artículo 4 del Convenio Europeo de Derechos Humanos", Universitas, n 25, 2017, pp. 104-105 y 109110.

2 JIMENA QUESADA, L., "Protection of refugees and other vulnerable persons under the European Social Charter", Revista de Derecho Político UNED, n 92, 2015, pp. 267-269 y 270-271.

${ }^{3}$ Recordamos aquí que la dignidad y la libertad de la persona se han calificado como la esencia misma del CEDH (STEDH de 29 de abril de 2002, caso Pretty contra Reino Unido, § 65). Vid. TAMER, S.V., La garantía judicial de los derechos sociales y su legitimidad democrática, 2018, pp. 140-141, con referencia a PECES BARBA, G., Derechos sociales y positivismo jurídico, Dykinson, Madrid, 1999, pp. 56-57; DÍEZ PICAZO, L.M., Sistema de derechos fundamentales, $2^{\mathrm{a}}$ ed., Aranzadi, Navarra, 2005, p. 41; y PÉREZ LUÑO, A.E., Los derechos fundamentales. Temas clave de la Constitución española, $8^{\text {a }}$ ed., Tecnos, Madrid, 2004, p. 187.
} 
de la capacidad económica de éste. Esto, unido a la falta de unos controles concretos y específicos de los mismos realmente efectivos es lo que ha llevado a calificarlos como "derechos financieramente condicionados", ${ }^{4}$ o de "meras promesas de corte politico o a lo sumo derechos incompletos". 5

Pero la protección de los derechos sociales no debe vincularse a cuestiones económicas, ${ }^{6}$ ni políticas. Se hace necesario partir de su universalidad y de la indivisibilidad de sus garantías.

El instrumento por excelencia de garantía de los derechos sociales a nivel internacional, aprobado en el marco del Consejo de Europa, es la Carta Social Europea (CSE). Si bien es cierto que en dicho contexto, el instrumento vinculante de protección de los derechos humanos es el Convenio Europeo de Derechos Humanos de 1950 (CEDH) -garantizado vía Tribunal Europeo de Derechos Humanos (TEDH)- el hecho de que el CEDH no reconozca derechos sociales, deja su reconocimiento a la citada CSE, como "instrumento de democracia social por excelencia" y específico de los derechos fundamentales sociales, ${ }^{7}$ siendo el Comité Europeo de Derechos Sociales (CEDS) su órgano de garantía.

Por otro lado, en el marco comunitario, aunque queda al margen de nuestro estudio, debemos señalar que la Unión Europea, en sus orígenes, no incorporaba derechos fundamentales, y mucho menos derechos de carácter social, dejando tal labor al Consejo de Europa con el CEDH. Este déficit, en la actualidad, se encuentra cubierto en tanto

\footnotetext{
${ }^{4}$ FERNÁNDEZ BURGUEÑO, B., "El trabajo forzado...", op. cit., p. 92; y CARMONA CUENCA, E., "Derechos sociales de prestación y obligaciones positivas del Estado en la jurisprudencia del Tribunal Europeo de Derechos Humanos", Revista de Derecho Político, no 100, 2017, pp. 1209-1210, con referencia a LAPORTA, F., "Los derechos sociales y su protección jurídica: introducción al problema", en BETEGÓN, J. (Coord.), Constitución y derechos fundamentales, CEPC, Madrid, 2004, pp. 300-301.

${ }^{5}$ Sobre esta cuestión, vid., por todos, ABRAMOVICH, V. / COURTIS, CH., Los derechos sociales como derechos exigibles, Trotta, 2002.

${ }^{6}$ Vid. FERNÁNDEZ BURGUEÑO, B., "El trabajo forzado...", op. cit., p. 92; y CARMONA CUENCA, E., "Derechos sociales...", op. cit., pp. 1209-1210, con referencia a LAPORTA, F., "Los derechos sociales y su protección jurídica: introducción al problema", en BETEGÓN, J. (Coord.), Constitución y derechos fundamentales, CEPC, Madrid, 2004, pp. 300-301. Sobre esta cuestión, vid., por todos, ABRAMOVICH, V. / COURTIS, CH., Los derechos sociales como derechos exigibles, Trotta, 2002. Al respecto, vid., también, LOPEZ AHUMADA, J.E., “Trabajo decente y...”, op. cit., pp. 9-10 y 18 y 32-33, quien señala que habría que tener en cuenta, además, los problemas que la globalización plantea para la protección social en estos casos, afirmando que "el proceso de globalización económica es frontalmente incompatible con la permanencia del denominado Estado del Bienestar".

${ }^{7}$ Vid., con carácter general, AKANDJI-KOMBE, J.F., "Carta Social Europea y Convenio Europeo de Derechos Humanos: perspectivas para la próxima década", Revista de Derecho Político, nº 67, 2006, pp. 387-407.
} 
que los Tratados incluyen entre sus valores rectores la igualdad y la dignidad humana; ${ }^{8}$ existe una Carta comunitaria de Derechos sociales fundamentales de los trabajadores (1989) $;{ }^{9}$ y, lo más importante, la Carta de Derechos Fundamentales de la Unión Europea (CDFUE) recoge expresamente un Titulo dedicado a los derechos sociales, ${ }^{10}$ siendo el Tribunal de Justicia de la Unión Europea (TJUE) el que actúe como "elemento catalizador" a la hora de reconocer estos derechos. ${ }^{11}$ Se está construyendo un "Pilar europeo de los derechos sociales". ${ }^{12}$ No obstante, a nivel comunitario debemos tener en cuenta que los derechos sociales, por un lado, son competencia nacional -siendo los Estados los que deben diseñar y aplicar dichos derechos de carácter prestacional-,

\footnotetext{
${ }^{8}$ Así, pej., el art. 2 TUE incluye la libertad y la dignidad como valores en una sociedad basada en la justicia y la solidaridad; y el art. 3 TUE se refiere a la "lucha contra la exclusión social y la discriminación".

9 La Carta comunitaria de Derechos sociales fundamentales de los trabajadores fue aprobada en el Consejo Europeo, celebrado los días 8 y 9 de diciembre de 1989. Toma como referentes, como indica en su propio Preámbulo, tanto a la Carta Social Europea como a los Convenios Internacionales de la OIT, y reconoce de forma expresa en su Pto. 10 la protección social de todo trabajador.

${ }^{10}$ Es el art. 1 CDFUE el que proclama la dignidad de todas las personas y el art. 5 CDFUE el que regula la prohibición de esclavitud y trabajo forzado, haciendo también referencia tanto a la servidumbre como a la trata de personas. Por su parte, el Cap. IV (arts. 27 a 38), bajo la rúbrica "Solidaridad", recoge derechos de contenido y dimensión social.

${ }^{11}$ El TJUE ofrece a los derechos sociales un tratamiento degradante, rebajándolos "a la consideración de excepción al ejercicio de las libertades económicas afectadas", haciendo primar las necesidades del mercado. Como ejemplos sobre derechos sociales, vid., asunto Viking (STJUE de 11 de diciembre de 2007 (C-438/05)), el asunto Laval (STJUE de 18 de diciembre de 2007 (C-341/05)), o el asunto Rüffert (STJUE de 3 de abril de 2008 (C-346/06)). Referencias en CARMONA CONTRERAS, A., "La afirmación de derechos en el espacio social europeo: luces y sombras de un proceso (todavía) en construcción", en MASALA, P. (Ed.), La Europa social: alcances, retrocesos y desafíos para la construcción de un espacio jurídico de solidaridad, CEPC, Madrid, 2018, pp. 54 y 64. Y sobre la omisión del TJUE al pronunciamiento del CEDS en los temas tratados en esos casos (Decisión de 3 de julio de 2013 sobre la Reclamación colectiva n 85/2012), vid. JIMENA QUESADA, L., "El papel del Comité Europeo de Derechos Sociales en el contexto de la crisis económica", en MASALA, P. (Ed.), La Europa social: alcances, retrocesos y desafíos para la construcción de un espacio jurídico de solidaridad, CEPC, Madrid, 2018, pp. 194-195.

12 Sobre la creación de un Pilar europeo de Derechos sociales, vid. Documento de Trabajo del CEDS sobre la relación entre el Derecho comunitario y la CSE: "The relationship between European Union law and the European Social Charter", de 15 de julio de 2014 (Disponible on line en: https://rm.coe.int/CoERMPublicCommonSearchServices/DisplayDCTMContent?documentId=090000168 06544ec). Vid., también, Opinión del Secretario General del Consejo de Europa sobre la iniciativa de la Unión Europea para establecer un pilar europeo de derechos socialesBruselas, de 26 de junio de 2017 (COM(2017) 250 final); y la Comunicación de la Comisión al Parlamento, al Consejo, al Comité Económico y Social Europea y al Comité de las Regiones titulada "Establecimiento de un pilar europeo de derechos sociales (SWD(2017) 201 final). Y Recomendación de la Comisión, de 26 de abril de 2017. Véase, también, el texto oficial de la Proclamación interinstitucional sobre el Pilar Europeo de Derechos Sociales del Parlamento Europeo, el Consejo y la Comisión (DOUE de 13 de diciembre de 2017 (2017/C 428/09)); y Resolución del Parlamento Europeo, de 19 de enero de 2017, sobre un pilar europeo de derechos sociales (2016/2095 (INI)); y Declaración de la Comisión Europea "Pilar europeo de derechos sociales: declaración del presidente Juncker, el vicepresidente Dombrovskis y la comisaria Thyssen un año después de su proclamación en Bruselas", de 13 de noviembre de 2018 (Disponible on line en https://ec.europa.eu/commission/sites/beta-political/files/european_pillar_one_year_on.pdf).
} 
quedándole a la Unión la competencia para coordinar dicha política social con el fin de que la misma no entorpezca el buen funcionamiento del mercado interior, ${ }^{13} \mathrm{y}$, por otro lado, debemos recordar que en atención a dicha coordinación, y fruto de la crisis económica con origen en el 2008 y de la obligación de estabilidad presupuestaria, las políticas sociales nacionales se han visto afectadas por las directrices comunitarias, que han conllevado una serie de recortes en gasto social con unos claros efectos adversos, especialmente, sobre los grupos sociales más vulnerables. ${ }^{14}$

A nivel nacional, nuestro texto constitucional garantiza los derechos sociales, si bien su garantía se ha visto condicionada a condiciones económicas. Esta tendencia se ha visto revertida en los últimos años, esencialmente vía jurisdiccional. Pero la falta de uniformidad en los pronunciamientos de nuestros Tribunales y de la voluntad política de reconocer el verdadero e importante papel del CEDS en este terreno, provoca que sea el Defensor del Pueblo el que, en atención a sus funciones constitucionales proteja los derechos sociales de los ciudadanos españoles, lo que lo convierte en una vía más efectiva, por su celeridad e inmediatez.

En este punto, a falta de un verdadero compromiso de los Estados con la realización efectiva de los derechos sociales, su garantía pasa por su protección jurisdiccional y por la labor de órganos como los Defensores del Pueblo. Es evidente que a nivel comunitario sigue faltando una decidida voluntad de reconocer y fortalecer los derechos sociales, ${ }^{15}$ y de colaborar entre las Organizaciones europeas para hacer realidad la protección multinivel de los derechos sociales y reconocer la Carta Social Europea

\footnotetext{
${ }^{13}$ El art. 3 TUE se refiere a las políticas de la Unión para combatir la exclusión social y llevar a cabo medidas de protección social, y el Tít. X TFUE sobre "Política social" se refiere expresamente a los derechos de la Carta Social Europea (aunque se omite la referencia expresa a la jurisprudencia del CEDS) (art. 151). En la misma línea se pronuncia la Carta comunitaria de los derechos sociales fundamentales de los trabajadores en su Pto. 27.

${ }^{14}$ CARMONA CONTRERAS, A., "La afirmación de...", op. cit., pp. 53-56, quien aconseja tener en cuenta las reflexiones en esta línea de GIUBBONI, S., "European citizenship and social Rights in times of crisis", German Law Journal, vol. 15, n 5, 2014, p. 952.

${ }^{15}$ Sobre esta apuesta, vid. CARMONA CONTRERAS, A., "La afirmación de...", op. cit., p. 70, quien refiriéndose al Pilar Europeo de Derechos Sociales (Comunicación de la Comisión sobre el establecimiento de un Pilar de derechos sociales, Bruselas, 26 de abril de 2017 (COM (2017) 250 final)) lo califica como una "decidida apuesta por un cambio de rumbo", destacando la petición realizada a la Comisión sobre el "reforzamiento de los derechos sociales mediante instrumentos concretos y específicos (legislación, mecanismos de elaboración de políticas e instrumentos financieros)". Sobre la implementación de este Pilar, así como su monitorización, vid. la Comunicación de la Comisión de 13 de marzo de 2018, Monitoring the implementation of the European Pillar of Social Right (COM (2018) 130 final), que incluía un "Paquete de Equidad Social" en el que se proponía la creación de una Autoridad Laboral Europea y la elaboración de una Recomendación sobre el acceso de los trabajadores a medidas de protección social. Vid. también, CANOSA USERA, R., "Carta Social Europea y Comité Europeo de Derechos Sociales", en MASALA, P. (Ed.), La Europa social: alcances, retrocesos y desafíos para la construcción de un espacio jurídico de solidaridad, 2018, p. 171.
} 
como una "Constitución Social para Europa" y el CEDS como "Jurisdicción Europea de Derechos Sociales". ${ }^{16}$

Es en este contexto donde el CEDS, órgano de garantía de la CSE, juega un papel esencial, sin perjuicio de que serán los Tribunales nacionales los que deberán hacer gala de su compromiso con el mismo para la realización y protección efectiva de los derechos sociales. Así, a falta de un criterio uniforme y coherente por parte de nuestros Tribunales, la única vía efectiva será el papel que desempeñe el Defensor del Pueblo como alto Comisionado de las Cortes generales para la defensa de los derechos y libertades constitucionales, entre los que se encuentran los derechos sociales. ${ }^{17}$

$\mathrm{Si}$ un derecho no goza de garantías, deja de ser un derecho. "solo cuando un determinado derecho está acompañado de garantías jurídicas es verdaderamente un derecho, sino se queda en una meditación sin consecuencias para el mundo jurídico". ${ }^{18}$ La pretendida universalidad e indivisibilidad de los derechos pierde todo sentido si no hablamos también de la indivisibilidad de sus garantías. ${ }^{19}$

\section{LA CARTA SOCIAL EUROPEA Y LOS DERECHOS SOCIALES}

La Carta Social Europea es el Tratado internacional más importante y el catálogo más completo de derechos sociales. Esto supone "el punto de referencia esencial del desarrollo de los derechos sociales en Europa". ${ }^{20}$ Como órgano de garantía, como ya ha quedado dicho, el CEDS. La Carta se considera la Constitución Social de Europa, y es

\footnotetext{
${ }^{16}$ En este sentido, JIMENA QUESADA, L., "El papel del Comité...”, op. cit., pp. 203-207 (pp. 206-207), quien destaca la necesaria colaboración entre el Consejo de Europa y la Unión Europea con el fin de evitar también asimetrías en el plano nacional y recuerda que para asegurar la convergencia social europea se aprobó el llamado "Proceso de Turín" (iniciado en la Conferencia política de alto nivel, celebrada en Turín los días 17 y 18 de octubre de 2014), que en la actualidad sigue abierto. Para más información, vid. https://www.coe.int/en/web/turin-process.

${ }^{17}$ Art. 54 CE y LO 3/1981, del Defensor del Pueblo.

${ }^{18}$ TEROL BECERREA, M., "Sobre la reforma de la Constitución Española de 1978”, Lex Social, $\mathrm{n}^{\circ} 1$ (2015), p. 116.

${ }^{19}$ Sobre esta idea, vid. JIMENA QUESADA, L., "El último en la defensa de los derechos sociales: la Carta Social Europea", RJUAM, $\mathrm{n}^{\circ}$ 29, 2014, pp. 171-189. También, CANOSA USERA, R., "Carta Social Europea...", op. cit., pp. 145 y 149; y AKANDJI-KOMBE, J.F., "Carta Social Europea...", op. cit., p. 390.

${ }^{20}$ SALCEDO BELTRÁN, C., "Reformas legislativas, incumplimientos de la Carta Social Europea y su invocación en los órganos judiciales", Actualidad, no 73, 2015, pp. 1-38 (p. 8), con referencia, entre otros, a BELORGEY, J.M., "La Carta Social Europea del Consejo de Europa y su órgano de control: el Comité Europeo de Derechos Sociales", Revista de Derecho Político, 2007, n. ${ }^{\circ}$ 70, p. 349.
} 
tomada como referente incluso en el ámbito comunitario, donde los derechos sociales reconocidos por la CDFUE se basan en los derechos garantizados por la citada Carta. ${ }^{21}$

La CSE fue aprobada en Turín el 18 de octubre de 1961 (ETS nº 035), viéndose ampliada, años más tarde, por tres Protocolos: en 1988 el Protocolo adicional $\mathrm{n}^{\circ} 1$, de 5 de mayo (ETS n ${ }^{\circ} 128$ ), que viene a incluir nuevos derechos sociales; en 1991, el Protocolo modificador $n^{\circ} 2$ (ETS $n^{\circ} 142$ ), reformando el mecanismo de control de la Carta; y, en 1995, el Protocolo adicional $n^{\circ} 3$ (ETS $n^{\circ} 158$ ), que incluye la posibilidad de interponer reclamaciones colectivas. ${ }^{22}$ Estas modificaciones llevaron a que un año más tarde, el 3 de mayo de 1996, se firmara en Estrasburgo el nuevo texto de la Carta Social Europea revisada (ETS n ${ }^{\circ} 136$ ), que contiene un total de 31 derechos, se abrió a firma el 3 de mayo de 1996 y entró en vigor el 1 de julio de $1999 .{ }^{23}$ La CSE revisada refleja todos los cambios introducidos por los tres Protocolos, junto con las interpretaciones que del texto convencional se habían ido generando por la labor de las resoluciones del CEDS. Su estructura reproduce la de la CSE originaria, añadiendo ocho nuevos derechos sociales a la Parte II (arts. 24 a 31). ${ }^{24}$

De todas las modificaciones operadas en la CSE debemos destacar, por la mejora que supuso para la protección de los derechos sociales, el Protocolo de 1995, que introdujo el mecanismo de reclamaciones colectivas de los derechos reconocidos en la Carta. No obstante, la posibilidad que abre la CSE revisada de ratificar su contenido de forma selectiva, sin necesidad de obligarse previamente al Protocolo de reclamaciones colectivas de 1995 debilita su eficacia, habiendo sido lo aconsejable que de forma generalizada se hubiera establecido la obligación de ratificar dicho Protocolo como

\footnotetext{
${ }^{21}$ Así, por ejemplo, el art. 6 TUE y el art. 18, la Sección relativa a la libertad de circulación de personas y, sobre todo, a la política social.

${ }^{22}$ Este Protocolo ha sido ratificado o aceptado por 15 países europeos: Bélgica, Bulgaria, Croacia, Chipre, Eslovenia, Finlandia, Francia, Grecia, Irlanda, Italia, Países Bajos, Noruega, Portugal, República Checa y Suecia. Su texto consta de un Preámbulo, seis Partes y un Anexo. Vid. GARCÍA GONZÁLEZ, G., "El sinuoso e inconcluso proceso de adhesión de España a la Carta Social Europea: resistencias, imperfecciones y retos de futuro", Lex Social, Vol. 9, no 1, 2019, p. 201, quien señala que el Protocolo ha sido calificado de "revolucionario desde el punto de vista procedimental"; con referencia a TEIXEIRA ALVES, L., El cumplimiento de la Carta Social Europea en materia de salarios: un estudio comparado de los ordenamientos laborales portugués, español e italiano, Barcelona, Atelier, 2014, pp. 15 y ss.

${ }^{23}$ Entre las novedades más importantes, podemos destacar, por poner algunos ejemplos, la inclusión de un artículo relativo a la prohibición de discriminación y la promoción de la igualdad de trato y oportunidades entre hombres y mujeres (arts. 20 y 27); el derecho a la dignidad en el trabajo (nuevo art. 26); o el derecho a la protección contra la pobreza y la exclusión social (nuevo art. 30).

${ }^{24}$ La CSE, ya sea la de 1961 o la revisada de 1996, ha sido ratificada por 43 de los 47 Estados miembros del Consejo de Europa. Solo Liechtenstein, Mónaco, San Marino y Suiza no han ratificado ninguno de estos Tratados. Entre los Estados que han ratificado la Carta están los 28 Estados que forman parte de la Unión Europea, como es el caso de España.
} 
condición previa a ratificar la CSE revisada. ${ }^{25}$ Esta ratificación a la carta, que permite que cada Estado elija los artículos a los que quiere obligarse, ${ }^{26}$ y que elijan su vinculación o no al sistema de garantías previsto en el Protocolo de 1995 -como ha sido el caso de España, que luego analizaremos-, si bien permite una mayor flexibilidad a la hora de su ratificación, debilita la eficacia de los derechos sociales reconocidos en dicho Tratado. $^{27}$

Podemos concluir que la CSE garantiza los derechos sociales y económicos fundamentales en el Consejo de Europa, como complemento del CEDH de 1950, centrado en los derechos civiles y políticos (que garantiza a través del TEDH). En la práctica, el hecho de que el CEDH no recoja los derechos sociales, provoca que el TEDH no se pronuncie, a priori, sobre los mismos, sino que lo tenga que hacer de manera indirecta. ${ }^{28}$ La técnica más empleada para proteger los derechos sociales por parte del TEDH ha sido la de las obligaciones positivas de los Estados, en relación con la exigencia de un nivel de vida digno. ${ }^{29}$ Esta técnica, consolidada desde el ya citado caso Airey contra Irlanda de 1979, permite interpretar que las obligaciones contenidas en el CEDH implican determinadas acciones positivas por parte de los Estados, con el fin de hacer reales y efectivos los derechos, independientemente de su tipo o naturaleza, en base, aunque no sólo, a la teoría universal de los derechos. ${ }^{30}$ Esta obligaciones son

${ }^{25}$ Art. D.2 Parte IV CSE revisada. Vid. GARCÍA GONZÁLEZ, G., "El sinuoso e inconcluso...”, op. cit., p. 202.

${ }^{26}$ Cada Estado Parte ha de obligarse, al menos, de 16 artículos, o 63 párrafos numerados, a su elección, además de 6 de los siguientes artículos de la Parte II: 1, 5, 6, 7, 12, 13, 16, 19 y 20. Vid. Art. A, Parte III CSE revisada.

${ }^{27}$ Esta forma de ratificación provoca que, salvo contadas excepciones como Francia y Portugal, que han ratificado toda la CSE, el resto de Estados lo haya hecho de forma fragmentada. Sobre esta variedad de situaciones, vid. GARCÍA GONZÁLEZ, G. "El sinuoso e inconcluso...", op. cit., p. 199, con referencia a BELORGEY, J.M., "La Carta Social Europea del Consejo de Europa y su órgano de control: el Comité europeo de Derechos Sociales", Revista de Derecho Político UNED, n 70, 2007, p. 351.

${ }^{28}$ Se recuerda en este punto que los Estados no han estado por la labor de ampliar el catálogo de derechos sociales reconocidos en el CEDH y, por tanto, de ampliar la protección del TEDH a dichos derechos. Sobre este tema, vid. GARCÍA VITORIA, I., "La jurisprudencia del Tribunal Europeo de Derechos Humanos sobre los derechos sociales", en MASALA, P. (Ed.), La Europa social: alcances, retrocesos y desafíos para la construcción de un espacio jurídico de solidaridad, CEPC, Madrid, 2018, p. 122, quien cita como trabajo de referencia MORTE GÓMEZ, C. / SALINAS ALCEGA, S., "Los derechos económicos y sociales en la jurisprudencia del Tribunal Europeo de Derechos Humanos", en EMBID IRUJO, A. (Dir.), Derechos económicos y sociales, 2009, pp. 359-412 (especialmente, pp. 369 у 373377).

${ }^{29}$ Sobre las obligaciones positivas, vid. CARMONA CUENCA, E., "Derechos sociales...", op. cit., pp. $1209-1210$ y $1216-1120$.

${ }^{30}$ STEDH de 9 de octubre de 1979, caso Airey contra Irlanda; y con anterioridad también se puede citar la STEDH de 13 de junio de 1979, caso Marckx contra Bélgica. Vid. GARCÍA ROCA, J., "La transformación del Convenio Europeo de Derechos Humanos", Revista General de Derecho Constitucional, $\mathrm{n}^{\circ}$ 28, 2018, pp. 15-16, quien hace referencia a que el TEDH incluso está exigiendo a los diferentes agentes estatales aprobar Protocolos de actuación, pej. en tema de control empresarial, 
mayores cuando es el propio Estado el que ha causado el daño o lesión; ${ }^{31}$ cuando se trata de personas bajo su tutela o protección; ${ }^{32}$ o cuando en situaciones de vulnerabilidad. ${ }^{33}$ No obstante, en este tipo de asuntos, a pesar de reconocer esas obligaciones positivas, y operando en la mayoría de los casos como un límite a las mismas, encontramos el conocido "margen de apreciación" nacional. ${ }^{34}$

Así las cosas, debemos aclarar en este punto dos cuestiones que creemos esenciales para visibilizar la importancia de la CSE y de la labor del CEDS. En primer lugar, aunque la CSE surge como complemento del CEDH -lo que provoca que sea calificada, y se perciba, como la "hermana pobre" del CEDH o como un "tigre de papel"-- ${ }^{35}$ la CSE es el primer instrumento internacional vinculante que contiene el catálogo más completo de derechos sociales. ${ }^{36} \mathrm{Y}$ en segundo lugar, el CEDS, a diferencia del TEDH, por su forma de aplicar el principio de igualdad de forma transversal y el principio de no discriminación a la hora de garantizar y reconocer los derechos sociales, ha provocado una mayor protección de los grupos más vulnerables, lo que ha llevado a calificar a la CSE de "Pacto Europeo de Democracia Social" o "Pacto Europeo por la Igualdad", 37 consiguiéndose así una protección de los grupos más vulnerables, ${ }^{38}$ garantizando

(Barbulescu contra Rumanía, STDH de 5 de septiembre de 2017, y Antovic y Mirkovic contra Montenegro, STEDH de 28 de noviembre de 2017).

${ }^{31}$ Por ejemplo, STEDH de 7 de mayo de 2002, asunto Bourdov contra Rusia, donde la víctima había participado en el accidente nuclear de Chernobyl; o en los casos de transfusiones de sangre sin los debidos controles que acabaron provocando una infección del virus VIH, como el asunto Oyal contra Turquía, STEDH de 23 de marzo de 2010.

${ }^{32}$ Como, por ejemplo, los casos de las personas en prisión, como el asunto Kaprykowsky contra Polonia, STEDH de 3 de febrero de 2009, donde un recluso con epilepsia no había recibido el tratamiento especializado que requería su caso.

33 Como, pej., el asunto Marzari contra Italia, STEDH de 4 de mayo de 1999, donde una persona con un alto grado de discapacidad había sido desalojada de su vivienda por impago. Vid. GARCÍA VITORIA, I., "La jurisprudencia del...", op. cit., pp. 136-140, quien cita a BINDER, C. / STEINER, E., "The European Court of Human Rights and Social Rights", en BINDER, C. (Ed.), Social Rights in the Case Law of Regional Human Rights Monitoring Institutions, Intersentia, Antwerp, 2016, pp. 52-59.

${ }^{34}$ Por todos, vid. GARCÍA ROCA, J., El margen de apreciación en la interpretación del Convenio Europeo de Derechos Humanos. Soberanía e integración, Civitas, Madrid, 2010.

35 AKANDJI-KOMBE, J.F., "Carta Social Europea...", op. cit., p. 388, quien recuerda que "En el mensaje especial que éste hizo público en mayo de 1954, en el cual se fijaba el mandato del Comité social intergubernamental encargado de redactar el proyecto de Carta, se definía el instrumento que debía ver la luz como el «pariente» del CEDH en el ámbito social".

${ }^{36}$ BELORGEY, J.M., BELORGEY, J.M., "La Carta Social Europea del Consejo...", op. cit., p. 349.

37 JIMENA QUESADA, L. / TOMÁS MALLÉN, B.S, "Hacia un estándar europeo común de igualdad: la contribución del Comité Europeo de Derechos Sociales", Revista de Derecho Político UNED, $\mathrm{n}^{\circ}$ 68, 2007, p. 342.

38 JIMENA QUESADA, L., "Protection of refugees...”, op. cit., pp. 250-251. 
derechos sociales vinculados especialmente con el disfrute de determinadas prestaciones sociales. ${ }^{39}$

Asimismo, no podemos olvidar que la CSE se basa en los principios de universalidad e indivisibilidad de los derechos humanos, confirmando que los derechos sociales son derechos humanos en pie de igualdad con los derechos civiles y políticos. ${ }^{40}$ No es posible establecer una separación absoluta entre las diversas categorías de derechos: sin unos es impensable disfrutar de los otros. ${ }^{41}$ Los derechos sociales no son sólo textos programáticos, dejados a voluntad de desarrollo por el legislador, ni deberían ser efectivos en mayor o menor medida en función de la voluntad del órgano jurisdiccional correspondiente. Si bien es cierto que estos derechos han sido calificados de "proteicos", debido a que permiten una interpretación elástica y expansiva, ${ }^{42}$ es labor del CEDS concretar su contenido. Así, con su jurisprudencia, con sus pronunciamientos y la interpretación que realiza de los mismos, los derechos sociales recogidos en la CSE pierden su carácter genérico, precisando el CEDS las obligaciones que su realización efectiva comporta. ${ }^{43}$

\footnotetext{
${ }^{39}$ LOPEZ AHUMADA, J.E., "Trabajo decente y...", op. cit., p. 15, recuerda que el empleo informal aparecido en las crisis económicas "impide desde el punto de vista de la igualdad promover políticas eficaces para remover las situaciones injustas" o discriminatorias, pues son ámbitos que "al no existir", quedan "sustraídos del ámbito de aplicación de las legislaciones laborales y de Seguridad Social".

${ }^{40}$ Así se recoge en la Declaración de Viena. Vid. Declaración y Programa de Acción de Viena, aprobada por la Conferencia Mundial de Derechos Humanos de la ONU el 25 de junio de 1993, según la cual: "Todos los derechos humanos son universales, indivisibles e interdependientes y están relacionados entre sí. La comunidad internacional debe tratar los derechos humanos en forma global y de manera justa y equitativa, en pie de igualdad y dándoles a todos el mismo peso" (Pto. 5). Disponible en https://www.ohchr.org/Documents/Events/OHCHR20/VDPA_booklet_Spanish.pdf. Vid. también, AKANDJI-KOMBE, J.F., "Carta Social Europea...,", op. cit., p. 394.

${ }^{41}$ Por todos, STEDH de 9 de octubre de 1979, caso Airey contra Irlanda. Vid. CARMONA CUENCA, E., "Derechos sociales...", op. cit., pp. 1213 y 1222-1223; con referencias a LÓPEZ GUERRA, L., "La protección de los derechos económicos y sociales en el Convenio Europeo de Derechos Humanos", en TEROL BECERRA, M. / JIMENA QUESADA, L. (Dirs.), Tratado sobre protección de derechos sociales, Tirant lo Blanch, Valencia, 2014, pp. 297-317; y a ESCOBAR ROCA, G., "Indivisibilidad y derechos sociales", Lex Social, no 2, 2012. Vid. CARRILLO SALCEDO, J.A., "Protección de los derechos humanos en el Consejo de Europa: hacia la superación de la dualidad entre derechos civiles y políticos y derechos económicos y sociales", Revista de Instituciones Europeas, Vol. 18, nº 2, 1991, pp. 431-454.

${ }^{42}$ Sobre esta consideración, vid. SANTOLAYA MACHETTI, P. / DÍAZ RICCI, S. "Los derechos económicos...", op. cit., pp. 249-286 (p. 260).

${ }^{43}$ Sobre este procedimiento, vid. NIVARD, C., "La justiciabilidad de los derechos sociales en el Consejo de Europa", Lex Social, Vol. 6, no 2, 2016, pp. 18-19, quien recuerda que sólo en tres el Comité de Ministros ha rechazado los argumentos del CEDS (ResChS(2002) 4 de 26 de marzo de 2002, relativa a la Decisión CEDS de 16 de noviembre de 2001, Confédération française de l'Encadrement (CFE-CGC) contra Fancia; ResChS(2002)2, de 21 de febrero de 2002, relativa a la decisión CEDS de 17 de octubre de 2001, STTK ry et Tehy ry contra Finlandia; y ResChS(2005)11, de 8 de junio de 2005, relativa à la Decisión CEDS, de 8 de diciembre de 2004, Centre européen des droits des Roms (CEDR) contra Grecia.
} 


\section{EL PAPEL DEL COMITÉ EUROPEO DE DERECHOS SOCIALES}

Para supervisar el cumplimiento de la CSE se creó el Comité Europeo de Derechos Sociales. Si bien la idea cuando se aprobó la Carta era que la misma se dirigiera al ámbito social, mientras el CEDH se centraba en la protección de los derechos civiles y políticos, la idea también era que las garantías de ambos documentos debieran ser idénticas, "sensiblemente idénticas o comparables", 44 diferenciándose ambos textos sólo por sus ámbitos de aplicación, esto es, por los derechos que cada texto garantiza. Pero la práctica y la configuración del TEDH, garante del CEDH, y la del CEDS, garante de la CSE, no ha podido ser menos idéntica y comparable. Esta diferencia dificulta la exigida indivisibilidad de los derechos, pues ambos instrumentos jurídicos obedecen a la misma finalidad, por lo que no es posible "una interpretación aislada de sus contenidos". ${ }^{45}$

La principal diferencia, y la que tiene consecuencias más prácticas, es el hecho de que el CEDS no tiene funciones jurisdiccionales, lo que el TEDH sí. De hecho, hasta 1998 el CEDS era denominado Comité de Expertos Independientes. ${ }^{46}$ En la actualidad lo integran quince miembros nombrados por un periodo de seis años, que son juristas elegidos a título individual e independientes. ${ }^{47}$ Asimismo, el TEDH exige agotar las vías nacionales, lo que no hace el CEDS. ${ }^{48}$ A pesar de estas características y de sus mecanismos de garantía y supervisión de la CSE, el CEDS se equipara en la práctica a un Tribunal, y sus Resoluciones y Conclusiones nada tienen que enviar a los fallos emitidos por el TEDH. Si se desea que la Carta sea un instrumento de protección efectiva de los derechos sociales, se impone que el Comité Europeo de Derechos Sociales demuestre su dinamismo interpretativo, ${ }^{49}$ y deje de ser considerado como una "rara avis" por los órganos jurisdiccionales internos, o como un mero órgano de

\footnotetext{
${ }^{44}$ AKANDJI-KOMBE, J.F., “Carta Social Europea...”, op. cit., p. 388.

${ }^{45}$ GARCÍA GONZÁLEZ, G., "El sinuoso e inconcluso...", op. cit., pp. 196-197. Con referencia a 7 RODRÍGUEZ PIÑERO, M., "La Carta Social Europea y la problemática de su aplicación", Revista de Política Social, no 118 (1978), pp. 6 y 7. Vid. el excelente análisis de CARRILLO SALCEDO, J.A., "Protección de los derechos humanos en el Consejo de Europa: hacia la superación de la dualidad entre derechos civiles y políticos y derechos económicos y sociales", Revista de Instituciones Europeas, vol. $18, \mathrm{n}^{\circ} 2$ (1991), pp. 431-454.

${ }^{46}$ Art. 25 Parte IV CSE revisada. Su Reglamento de funcionamiento interno fue adoptado el 29 de marzo de 2004, y revisado por última vez el 10 de septiembre de 2019. Disponible on line: https://rm.coe.int/rules-of-the-european-committee-of-social-rights-rev-2-bil/1680788a3d.

${ }^{47} \mathrm{La}$ decisión de que su composición fuera de 15 miembros se adoptó por el Consejo de Ministros durante su $751^{\circ}$ Encuentro, del 2 al 7 de mayo de 2001.

${ }^{48}$ AKANDJI-KOMBE, J.F., "Carta Social Europea...", op. cit., pp. 400-401, para quien la diferencia entre los recursos individuales ante el TEDH y los colectivos ante el CEDS no es tan grande, en tanto que, en último término, en la práctica, las reclamaciones colectivas se componen de situaciones individuales y particulares.

${ }^{49}$ AKANDJI-KOMBE, J.F., “Carta Social Europea...”, op. cit., p. 392.
} 
monitoreo del Consejo de Europa. El CEDS debería desplazar el protagonismo del TEDH en el terreno de los derechos sociales, sin perder de vista el principio de indivisibilidad de los derechos sociales, corrigiendo la "omisión expiatoria" del CEDH. ${ }^{50}$

Así las cosas, antes de destacar la importancia de los pronunciamientos de la llamada jurisprudencia del CEDS -siendo conscientes de que no son pronunciamientos judiciales-, debemos recordar brevemente los mecanismos de protección y vigilancia que dicho instrumento maneja y que se recogen en la CSE revisada, que son los mismos que los de la CSE de 1961, esto es, el sistema de Informes, más el sistema de Reclamaciones colectivas incluido por el Protocolo de 1995, ya citado. ${ }^{51}$

El sistema de Informes se basa en los informes que, anualmente, los Estados remiten al CEDS explicando la forma en la que cumplen la CSE. Cada año los Estados mandan un informe sobre un grupo temático. ${ }^{52}$ Tras su análisis por parte del CEDS y de su Decisión, el Comité de Ministros emitirá las correspondientes Recomendaciones o Resoluciones. La cuestión es que en este sistema las Decisiones del CEDS van a dejarse en manos de la voluntad nacional de ejecutarlas. Por otro lado, el sistema de Reclamaciones colectivas es el segundo mecanismo de control de la CSE. Las reclamaciones colectivas representan un mecanismo dotado de una gran eficacia, pues su carácter colectivo provoca un efecto desincentivador a nivel nacional, provocando igualmente, un descenso de los litigios en relación con el derecho social objeto de análisis, aumentando así su justiciabilidad. El problema de este sistema es que a él sólo pueden acudir los Estados que hayan ratificado el Protocolo de 1995 que lo introduce, lo que no sucede en España, como luego veremos. Y, además, aunque por su carácter contradictorio puede asemejarse a un procedimiento judicial, no lo es y las decisiones del CEDS no son vinculantes ni ejecutivas, requiriendo de la correspondiente Recomendación por parte del Comité de Ministros, ${ }^{53}$ aunque sea el CEDS el que tenga

50 JIMENA QUESADA, L., "Las grandes líneas jurisprudenciales del Comité Europeo de Derechos Sociales: Tributo a Jean Michel Belorgey”, Lex social, Vol. 7, n 1, 2017, p. 5, en cuya nota 4 recuerda la necesidad de superar la "indivisibilidad desigual" entre derechos civiles y derechos sociales. Así lo ha criticado BELORGEY, J.M., "Le Conseil de l'Europe au milieu du gué”, Revue administrative, $\mathrm{n}^{\circ} 372$, 2010, pp. 625-626.

${ }^{51}$ Art. C Parte IV CSE revisada (arts. 21-29) y Art. D Parte IV CSE revisada y el ya citado Protocolo de 1995. Vid. también, Parte VII y VIII del Reglamento de funcionamiento del CEDS, antes citado.

${ }^{52}$ Existen cuatro grupos temáticos: el Grupo 1 se centra en el empleo, la formación y la igualdad de oportunidades; el Grupo 2 analiza los temas de salud, seguridad social y protección social; el Grupo 3 trata sobre derechos relacionados con el trabajo; y el Grupo 4 analiza las cuestiones relacionadas con niños, familia y migrantes.

${ }^{53}$ Hasta el Protocolo de 1995, el Comité de Ministros era como un instrumento de apelación, pudiendo invalidar las Decisiones del CEDS, comprometiendo así su actividad y efectividad. Vid. AKANDJIKOMBE, J.F., “Carta Social Europea...”, op. cit., pp. 395-396. 
la última palabra. ${ }^{54}$ En resumen, el sistema de protección específico de la Carta se basa tanto en el envío de Informes de los Estados al CEDS, como -desde 1998- en la posibilidad de interponer Reclamaciones colectivas ante el citado Comité. ${ }^{55}$ Esto es, con carácter general, es el CEDS el encargado de fijar el alcance y contenido de los derechos sociales reconocidos en la Carta. Por ello, la "jurisdiccionalización del mecanismo de supervisión de la CSE" puede ser un gran acierto pues, ${ }^{56}$ como ha quedado dicho, su justiciablidad no se puede vincular a su naturaleza, ${ }^{57} \mathrm{y}$, en realidad los derechos sociales no son compartimentos estancos de los derechos civiles y políticos ${ }^{58}$ como tampoco lo son sus garantías. ${ }^{59}$

Es esencial, para garantizar de forma efectiva los derechos sociales garantizados en la CSE, reconocer la eficacia y efecto vinculante de las Decisiones y Resoluciones del CEDS. Incluso a falta de tal naturaleza en la actualidad, no se puede negar la importancia de sus decisiones, que han influido incluso en la interpretación que el TEDH hace a su vez del CEDH en ciertos aspectos sociales. ${ }^{60}$ No obstante, haciendo

54 GARCÍA GONZÁLEZ, G., "El sinuoso e inconcluso...”, op. cit. Sobre este procedimiento, vid. NIVARD, C., "La justiciabilidad de...", op. cit., pp. 18-19.

55 Al respecto, sobre los mecanismos de garantía de la Carta Social Europea, vid. el Protocolo Adicional sobre la reforma de los mecanismos de supervisión, de 21 de octubre de 1991 (ETS n 142) y el Protocolo Adicional estableciendo un sistema de quejas colectivas, de 9 de noviembre de 1995, que entró en vigor el 1 de julio de 1998 (ETS no 158). Vid. CARMONA CUENCA, E., "Derechos sociales...", op. cit., p. 1213. Sobre la labor especializada del CEDS, vid. CANOSA USERA, R., "Carta Social Europea...", op. cit., pp. 155-165; y BELORGEY, J.M., "La Carta Social...”, op. cit., pp. 353-356 y 360 ha destacado las virtudes del procedimiento de las Reclamaciones colectivas destacando el hecho de su simplicidad y efectividad, afirmando que así "El Comité Europeo de Derechos Sociales hace Derecho; esta es precisamente su originalidad; no se interesa solamente por los buenos usos; ... más allá del Derecho, quiere que las prácticas sean buenas, y si un texto es excelente pero la práctica es mala, esto también es inaceptable".

${ }^{56}$ NIVARD, C., "La justiciabilidad de...", op. cit., pp. 15-16. Las otras dos vías son la socialización de los derechos del CEDH y la invocación a nivel nacional de los derechos de la CSE.

${ }^{57}$ NIVARD, C., "La justiciabilidad de...", op. cit., pp. 14-15, con referencia a HERREROS LOPEZ J. M., "La justiciabilidad de los derechos sociales", Lex social, n ${ }^{\circ} 1$, 2011; y a NIVARD, C., La justiciabilité des droits sociaux. Etude de droit conventionnel européen, Bruylant, 2012, pp. 143-160.

${ }^{58} \mathrm{El} \mathrm{TEDH}$ ha señalado que "admitiendo que la protección de los derechos civiles tiene implicaciones sociales, por lo que el ámbito de aplicación del Convenio puede extenderse al terreno de los derechos económicos y sociales. No son compartimentos estancos". En este sentido, un primer pronunciamiento sobre la protección de los derechos sociales se plasmó en el caso Airey contra Irlanda, de 9 de octubre de 1979, donde el TEDH se hizo eco de la Carta Social Europea Así pej., la libertad sindical (art. 11 CEDH) o el derecho a la educación (art. 2 Protocolo Adicional no 1 al CEDH). Sobre esta cuestión, citando como referente el caso Airey contra Irlanda, STEDH de 9 de octubre de 1979, vid. GARCÍA VITORIA, I., "La jurisprudencia del...", op. cit., p. 123.

${ }^{59}$ STEDH de 9 de octubre de 1979, caso Airey contra Reino Unido.

${ }^{60}$ BURGOS ADURIZ, A. "La protección del contenido esencial de la libertad sindical en la Unión Europea ¿cómo afectaría esta situación a la futura adhesión de la Unión Europea al Convenio Europeo de Derechos Humanos? Contradicciones con la jurisprudencia del Tribunal Europeo de Derechos Humanos", Revista de Estudios Europeos n $^{\circ} 71$, 2018, pp. 260 y 262. La autora señala también la influencia de la Carta Social Europea y su interpretación por el CEDS en la CDFUE y en su interpretación por parte del 
honor a la verdad, a pesar de que el TEDH sí que se va a referir a la Carta Social Europea, se referirá al CEDS en muchísimas menos ocasiones. ${ }^{61}$ Podríamos llegar incluso a afirmar que el TEDH ha recurrido en temas laborales y sociales en más ocasiones a los Convenios Internacionales de la OIT que a los pronunciamientos del CEDS, haciendo así de menos a los pronunciamientos de este último organismo hermano. ${ }^{62}$

Así las cosas, sin detenernos en este trabajo en el papel del TEDH, debemos señalar que el mismo, especialmente en los últimos años, ha ido haciendo frente a los recortes sociales y a las medidas regresivas utilizando, de forma complementaria a las obligaciones positivas de los Estados respecto del cumplimiento de los derechos, el principio de proporcionalidad. ${ }^{63}$ acotando el margen de apreciación nacional bajo la inspiración de la universalidad de los derechos, sin que pueda prevalecer discriminación por razón de nacionalidad. ${ }^{64}$ Asimismo, el TEDH ha venido aplicando el criterio de la "garantía de un mínimo vital", enlazado con la prohibición de tratos inhumanos y degradantes (art. $3 \mathrm{CEDH}$ ), donde el TEDH viene a concluir que aunque el CEDH no garantiza un bienestar económico, porque son los Estados los que tienen que determinar su política económica, los recortes sociales no pueden llegar bajo ningún concepto a poner en riesgo la vida o integridad de una persona y menos en las víctimas de estas prácticas. ${ }^{65}$

TJUE, que la ha utilizado como parámetro de control y como elemento para desarrollar las políticas sociales de la Unión. Al respecto, vid. JIMÉNEZ GARCÍA, F., "La Carta Social Europea (Revisada): Entre el desconocimiento y su revitalización como instrumento de coordinación de las políticas sociales europeas", Revista Electrónica de Estudios Internacionales, nº 17, 2009, pp. 79-124.

${ }^{61}$ Así, por ejemplo, en el asunto Sørensen y Rasmussen contra Dinamarca, STEDH de 11 de enero de 2006, o en el asunto Winterstein y otros contra Francia, STEDH de 17 de octubre de 2013, el TEDH hace suyo el enfoque evolutivo del CEDS plasmado en la Decisión de fondo de 22 de mayo de 2003, dictada en la Reclamación colectiva $n^{\circ} 12 / 2002$. Pero, como ha quedado dicho, éstas son contadas ocasiones. Por ello, se sigue reclamando un mayor diálogo judicial. Al respecto, vid. JIMENA QUESADA, L., "El papel del Comité...", op. cit., pp. 192-193.

${ }^{62}$ Vid., por todos, Reclamación $\mathrm{n}^{\circ} 111 / 2014$, de la Confédération générale grecque du travail (GSEE); y la Reclamación $\mathrm{n}^{\circ}$ 165/2018, Fédération panhellénique des pensionnés des télécommunications du groupe OTE (FPP-OTE).

${ }^{63}$ STEDH de 12 de octubre de 2004, asunto Kjartan Ásdmunsson contra Islandia; y STEDH de 7 de mayo de 2013, asunto Koufaki y ADEDY contra Grecia. Al respecto, vid. GARCÍA VITORIA, I., "La jurisprudencia del...", op. cit., pp. 126-127.

${ }^{64}$ CANOSA USERA, R., "Carta Social Europea...”, op. cit., pp. 152-153.

${ }^{65}$ Principio que la CSE reconoce como el derecho a la protección social contra la pobreza y contra la exclusión social (art. 30). Al respecto vid. Decisión del TEDH, asunto Frimu y otros contra Rumania, de 13 de noviembre de 2012. En este sentido, GARCÍA VITORIA, I., "La jurisprudencia del...", op. cit., p. 128, quien señala como origen de este criterio la Decisión de 23 de abril de 2002, asunto Larioshina contra Rusia, Decisión poco aplicada, como recoge LÓPEZ GUERRA, L., "Crisis económica...., op. cit., pp. 404-405. 
La cuestión es que, sea por el motivo que sea, los pronunciamientos del TEDH han venido haciendo sombra e invisibilizando los pronunciamientos del CEDS, mucho más novedosos en materia de derechos sociales, como podemos comprobar por la protección otorgada a los grupos más vulnerables o el reforzamiento de la perspectiva de género a través de la no discriminación y la exigencia de igualdad. ${ }^{66}$ Mientras que el TEDH ha sido muy "tibio" en muchos de sus pronunciamientos recurriendo en estos casos al margen de apreciación nacional, la influencia de los pronunciamientos del CEDS ha sido determinante.

Deberíamos tener en cuenta y valorar imponer la obligación de la remisión por parte de los Tribunales nacionales al mismo CEDS como una técnica más para proteger los derechos sociales. Poco se puede esperar de la jurisprudencia del TEDH en materia de derechos sociales, que suele inaceptar las demandas que recibe con base en los mismos. ${ }^{67}$

No obstante, y como muchos autores han puesto de manifiesto -con lo que coincidimos plenamente-, es que en esta protección parece olvidarse la existencia de la Carta Social Europea y su carácter igualmente vinculante para los Estados y con la importante labor del CEDS. ${ }^{68}$

Resulta evidente, por tanto, la trascendencia que tiene en estos momentos conocer la CSE, la jurisprudencia del CEDS, órgano que se encarga de controlar su aplicación, así como la articulación del derecho interno y del internacional cuando aquél incumple las

\footnotetext{
${ }^{66}$ Vid. GARCÍA ROCA, J., "La transformación del...", op. cit., p. 13, quien afirma que el universalismo refuerza la garantía de los derechos. Ya ha quedado dicho cómo el hecho de que se excluyeran los derechos sociales expresamente del CEDH y se dejara su reconocimiento y protección a la Carta Social Europea y al CEDS, ha provocado que "el TEDH mediante una jurisprudencia expansiva ha protegido algunos derechos sociales por carambola (par ricochet), esto es, de manera indirecta, poniéndolos en conexión con derechos civiles, siguiendo una interpretación sistemática, o extendiendo los contenidos de derechos viejos" ${ }^{66}$ Esto lo ha venido haciendo el TEDH a través de diversas técnicas, sin olvidar, claro está, los criterios jurídicos interpretativos de carácter general aplicables a todos los derechos garantizados por el CEDH como es el de proteger "derechos no teóricos e ilusorios, sino concretos y efectivos", y la idea de que los Convenios son instrumentos vivos que deben ser aplicados "a la luz de las condiciones de vida actuales". Por ejemplo, respectivamente, vid. STEDH de 13 de mayo de 1980, caso Ártico contra Italia y STEDH de 5 de abril de 1978, caso Tyrer contra Reino Unido. Sobre esta cuestión, vid. SANTOLAYA MACHETTI, P. / DÍAZ RICCI, S. "Los derechos económicos...”, op. cit., pp. 249-286 (pp. 250-251).

67 Vid. SALCEDO BELTRÁN, C., "Derechos sociales y su garantía: la ineludible aprehensión, disposición e implementación de Carta Social Europea (Constitución Social de Europa)", Revista de Derecho Social, $\mathrm{n}^{\circ} 83,2018$, p. 52, quien recuerda, entre otras, la directriz más conocida, la de 7 de mayo de 2013, Ioanna Koufaki y Confederación de sindicatos de funcionarios públicos (ADEDY) contra Grecia. ${ }^{68}$ BURGOS ADURIZ, A. "La protección del...", op. cit., pp. 268-269, con referencias a PÉREZ ALBERDI, M.R., "La jurisprudencia social del Tribunal Europeo de Derechos Humanos", Lex Social, no 1, 2011, pp. 93-105 (pp. 93-94).
} 
obligaciones derivadas de éste, dedicándose este trabajo a su estudio, puesto que es manifiesto su desconocimiento, procediendo a continuación al análisis de los incumplimientos señalados. ${ }^{69}$

Debemos recordar que la CSE tiene carácter vinculante y la importante labor del CEDS. ${ }^{70}$ El CEDS a través del cumplimiento del principio de efectividad, ha dado un paso más y ha pasado de imponer a los Estados obligaciones de resultado más allá de las obligaciones de medios. Según el CEDS sí se requiere que las medidas adoptadas apunten a conseguir el objetivo fijado por la Carta y que tales medidas produzcan los efectos susceptibles de ser esperados teniendo en cuenta dicho objetivo. ${ }^{71}$

Por todo ello, dada la evolución y la innovación experimentada en los pronunciamientos del CEDS nos referiremos al mismo bajo el convencimiento, como ha mantenido algún autor, que la protección de los derechos sociales pasa por entender la Carta Social Europea como el último bastión de protección de los derechos sociales en Europa, ${ }^{72}$ y el CEDS su máximo garante.

\section{LA ASIGNATURA PENDIENTE DE ESPAÑA EN DERECHOS SOCIALES: LA VINCULACIÓN REAL AL COMITÉ EUROPEO DE DERECHOS SOCIALES}

\section{La necesaria ratificación efectiva de la Carta Social Europea y sus Protocolos}

España firmó la CSE revisada el 23 de octubre de 2000 pero, alegando la necesidad de adaptar algunos aspectos de la legislación española, pospuso su completa ratificación, dejando en el aire igualmente la firma del Protocolo de 1995. Esta posibilidad, es a la que se acogió el Gobierno español en su Acuerdo de febrero de 2019, por el que finalmente dio el paso para ratificar la CSE revisada, ${ }^{73}$ dejando al trámite parlamentario

\footnotetext{
69 SALCEDO BELTRÁN, C., "Reformas legislativas, incumplimientos de la Carta Social Europea y su invocación en los órganos judiciales", Actualidad, n 73, 2015, pp. 1-38.

70 BURGOS ADURIZ, A. "La protección del...", op. cit., pp. 268-269, con referencias a PÉREZ ALBERDI, M.R., “La jurisprudencia social...”, op. cit., pp. 93-105 (pp. 93-94).

${ }^{71}$ Así, por ejemplo, en los casos del trabajo infantil a la hora de fija la edad de 15 años como edad de admisión al trabajo, en el asunto Comisión Internacional de Juristas contra Portugal. Vid. AKANDJIKOMBE, J.F., “Carta Social Europea...”, op. cit., pp. 392-393.

${ }^{72}$ Sobre esta idea, vid. JIMENA QUESADA, L., "El último bastión...”, op. cit., pp. 171-189.

${ }^{73}$ Las Juezas y Jueces para la Democracia, publicaron el 6 de febrero de 2019 un Comunicado sobre la ratificación, por parte de España, de la Carta Social Europea revisada y demandan "que el compromiso con los derechos sociales y con sus garantías sea real y pleno, y se insta al Gobierno y al resto de las fuerzas políticas a que lleven a cabo la declaración específica de supervisión del Comité Europeo de Derechos Sociales de forma simultánea a la ratificación de la Carta Social Europea Revisada". Para
} 
la ratificación completa la CSE revisada. Si bien es cierto que, en sede parlamentaria, en el mismo momento de la ratificación, hubiera sido posible corregir la exclusión del Protocolo que se produjo en el Acuerdo de 1 de febrero de 2019, a través de la manifestación ad hoc, la disolución de las Cortes deja en el aire lo que habría podido pasar.

Antes de la CSE revisada de 1996, España ratificó la CSE de 1961 en abril de 1980 así como los diferentes Protocolos de 1988 y de 1991. ${ }^{74}$ Como hemos visto, si bien España firmó la CSE revisada en el año 2000, no ha sido hasta el año 2019, hasta casi 25 años de aprobación de dicho documento, cuando España se decidió a ratificarlo y no de forma completa, como ha quedado dicho, sino dejando fuera la ratificación del Protocolo de 1995, lo que lleva a excluir la posibilidad de que España pueda formular reclamaciones colectivas frente al CEDS por incumplimiento de los derechos sociales garantizados por la CSE. ${ }^{75}$ Lo que, en resumidas cuentas, resta efectividad a los derechos sociales.

La falta de ratificación del texto revisado y del reconocimiento, salvo honrosas excepciones, de la excelente labor del CEDS, ha provocado que nuestros legisladores hagan la vista gorda sobre los derechos sociales y los efectos de la crisis sobre los mismos y que los Tribunales, salvo como ha quedado dicho, honrosas excepciones, vengan considerando que los derechos sociales reconocidos en dicho texto no son directamente vinculantes. Lo cual no es cierto, como luego veremos. Por estos motivos reiteramos la necesidad de ratificación de la CSE y del reconocimiento de su eficacia vinculante, así como las de los pronunciamientos del CEDS, máxime cuando éste en los últimos años no se ha limitado a verificar y comprobar el cumplimiento de la CSE, sino que ha concretado el contenido de los derechos sociales en ella recogidos y se ha atrevido a indicar a los Estados las medidas para atajar los posibles incumplimientos.

La falta de compromiso de España se ha reflejado en las condenas del CEDS a nuestro país. ${ }^{76}$ El CEDS se ha pronunciado sobre España, especialmente a raíz de la crisis

Juezas y Jueces para la Democracia dicho retraso era injustificable e inaceptable, en especial en el marco de nuestra Constitución que define a la nación como un Estado social y democrático de Derecho y aunque se felicitan por el Acuerdo del Gobierno, consideran que no es suficiente al haber excluido la ratificación del Protocolo de reclamaciones colectivas de 1995.

74 Al respecto, vid. el completo estudio de RODRÍGUEZ PIÑERO, M., "Antecedentes, génesis y significado de la Carta Social Europea", Revista de Política Social, no 53, 1962, pp. 133-195. No obstante, en el Instrumento de ratificación de 1980 se indica que España interpretará y aplicará los artículos 5 y 6 de la CSE en relación con el artículo 31 y el anexo a la Carta, de manera que sus disposiciones sean compatibles con las de los artículos 28, 37, 103.3 y 127 de la Constitución española.

${ }^{75}$ Sobre esta cuestión, vid. GARCÍA GONZÁLEZ, G., "El sinuoso e inconcluso...”, op. cit., pp. 193-219.

${ }^{76}$ GARCÍA GONZÁLEZ, G., "El sinuoso e inconcluso...”, op. cit., p. 210, quien critica que no se tenga en cuenta el "enorme potencial de justiciabilidad y efectividad" de la CSE y de la vía de las 
económica, en numerosas ocasiones en relación con las medidas restrictivas de derechos sociales, de igual manera que lo hiciera en el caso griego, ${ }^{77}$ argumentando la violación que dichos comportamientos producen respecto de la CSE.

Con carácter general, las Conclusiones XXI-3 (2018) del CEDS, publicadas el 25 de marzo de 2019, manifiestan que la mayoría de los Estados han evolucionado positivamente, pero que tienen dificultades para observar todos los requerimientos de la CSE. ${ }^{78} \mathrm{Y}$, en el caso de España se evidencia que los mismos fallos que se reflejaron en los Informes remitidos en 2010 y 2014 se han reiterado en 2018, siendo especialmente destacable los incumplimientos relacionados con la distribución irregular de la jornada de trabajo o con la falta de una remuneración equitativa que garantice un nivel de vida decente. Por estos motivos, entre otros, el CEDS condena a España por la regulación de un plazo irrazonable de preaviso para los despidos objetivos, así como por la regulación (dejada en manos del empresario) de las Condiciones del Convenio colectivo, y por la regulación del sistema de arbitraje como fórmula para finalizar una huelga.

Esto evidencia la falta de compromiso español con los derechos sociales, lo que ha llevado desde hace años a que hayan sido los Tribunales nacionales los principales defensores de los derechos sociales, vía CSE - lo que habría sido más sencillo si se hubiera reconocido la eficacia de las reclamaciones colectivas previstas en el CEDS-. El origen de la revolución judicial, más allá de pronunciamientos aislados, fue la aprobación de la Ley 3/2012, de 6 de julio, de medidas urgentes para la reforma del mercado laboral. Aquí los Tribunales nacionales procedieron a aplicar la CSE como estándar de protección más favorable, declarando inaplicable la legislación nacional en algunos de los casos enjuiciados, por ser contraria al compromiso internacional asumido por España.

reclamaciones colectivas del Protocolo de 1995. Vid. JIMENA QUESADA, L. y SALCEDO BELTRÁN, C., "Desafíos para la...", op. cit., p. 277; con referencia a BAJO GARCÍA, I., "La reforma laboral a la luz de la Carta Social Europea. Convergencias y divergencias entre el Tribunal Constitucional y el Comité Europeo de Derechos Sociales", Revista General de Derecho del Trabajo y de la Seguridad Social, $\mathrm{n}^{\circ}$ 40, 2015, p. 158; y JIMENA QUESADA, L. y SALCEDO BELTRÁN, C., "Desafíos para la...", op. cit., p. 279.

77 JIMENA QUESADA, L. "Las grandes líneas jurisprudenciales...”, op. cit., pp. 19-20, con referencia a dos decisiones de fondo del CEDS de 23 de mayo de 2012 de resolución de las Reclamaciones colectivas $n^{\circ} 65 / 2011$ y n ${ }^{\circ} 66 / 2011$, ambas contra Grecia, donde el CEDS sostuvo en su argumentación jurídica: "La crisis económica no debe traducirse en una reducción de la protección de los derechos reconocidos por la Carta".

${ }^{78}$ Se demuestra una falta de compromiso estatal, lo que se evidencia en el hecho de 580 Conclusiones presentadas, sólo 276 son de conformidad, pero 206 de no conformidad y 98 son aplazadas ante la falta de información. 
De este modo, algunas resoluciones judiciales se alejan del uso residual de la CSE y se inicia una tímida corriente de resoluciones judiciales que optan por la aplicación directa de la misma, ya no como un tratado de referencia, consulta, o apoyo argumental, sino como una norma más integrada en el ordenamiento jurídico español, susceptible de ser aplicada directamente en la resolución de las diferentes controversias que puedan plantearse en sede jurisdiccional.

En conclusión, y respecto de la ratificación del texto de la CSE revisada, como ya dijera el Consejo de Estado en su Dictamen 1740/2000, de 11 de mayo de 2000: "la ratificación de la Carta Social Europea revisada no sólo no plantea problemas de aplicación en España, sino que concuerda en buena medida con las previsiones y objetivos del Derecho interno, de modo que su ratificación no implicará la necesidad de modificar la legislación vigente". En idéntico sentido se había pronunciado casi medio año antes la Secretaria General Técnica del Ministerio de Trabajo y Asuntos Sociales, en cuyo Informe de 26 de noviembre de 1999 subrayaba que, a excepción de determinados artículos puntuales relacionados con las vacaciones anuales pagadas y los servicios de higiene laboral, el reconocimiento a nivel supranacional de nuevos derechos "no plantea problemas de aplicación en nuestro país, ya que concuerda con nuestro derecho interno, por lo que su ratificación no implicaría la necesidad de modificar nuestra legislación". Por ello, no es comprensible que España, a día de hoy, siga sin ratificar la CSE revisada en su totalidad, con la posibilidad de las reclamaciones colectivas introducida por el Protocolo de 1995, que la misma incorpora. Al dejar fuera el citado Protocolo la ratificación de la Carta Social Europea revisada se convierte en papel mojado al restar visibilidad, exigibilidad y efectividad de los derechos consagrados en la misma.

Si tenemos en cuenta que los derechos reconocidos por la CSE revisada son los mismos que a su vez garantiza la CDFUE, cuya fuerza vinculante directa no es cuestionada por nadie, es evidente que la falta de reconocimiento de estos derechos obedece a cuestiones que no son jurídicas. ${ }^{79}$

A falta de una clara voluntad política, a falta de que el CEDH se "socialice" y el TEDH puede entrar a enjuiciar dichos derechos; a falta de que los mecanismos de control de la CSE sean reconocidos por todos los Estados y tengan fuerza vinculante, es más que evidente que es a nivel nacional donde se tendrá que concretar la justiciabilidad de los derechos sociales. En este punto, las vías pueden ser tanto a través del Defensor del

79 GARCÍA GONZÁLEZ, G., "El sinuoso e inconcluso...”, op. cit., p. 212, quien habla de voluntad política o de criterios de oportunidad política; y con referencia a JIMENA QUESADA, L., "Retos pendientes del estado social español...", op. cit., pp. 51-59. 
Pueblo como a través de los Tribunales nacionales. La falta de la firma y ratificación de la CSE revisada y del Protocolo de 1995 resta efectividad a la citada norma y, por lo tanto, a la justiciabildiad de los derechos sociales. ${ }^{80}$

\section{Los Tribunales nacionales}

En los últimos años, especialmente a raíz de las crisis económica, algunos Tribunales y jueces españoles han procedido a aplicar la CSE como estándar de protección más favorable para los derechos de los ciudadanos e inaplicar la normativa nacional bajo el argumento de que la misma es contraria a la CSE y por tanto, vía art. $10 \mathrm{CE}$, proceden a su aplicación e interpretación más favorable para los ciudadanos. ${ }^{81}$ Esto es, aplicación directa de la CSE.

Como ahora analizaremos, han venido siendo los Tribunales nacionales los que se han hecho eco de los pronunciamientos del CEDS o bien han aplicado directamente la CSE vía control de convencionalidad. Nuestro TC, al hilo de resolver asuntos como el análisis de la constitucionalidad de la controvertida Ley 3/2012, de Medidas urgentes para la reforma laboral (con su Sentencia 119/2014), ha venido rechazando tal práctica. Lo que, de forma totalmente contraria, basándose en la Decisión de 23 de mayo de 2012 del CEDS ( $n^{\circ}$ de Reclamación 65/2011) han venido haciendo muchos Tribunales inferiores, aplicando la CSE y desplazando a la normativa nacional. Por su parte, desde la Unión Europea, el TJUE ha tomado la vía de en medio y en la Sentencia de 5 de febrero de 2015, en el asunto Nisttahuz Poclava, se declaró incompetente para analizar la problemática surgida en torno a los contratos para emprendedores. Esta actitud, como es lógico, resta efectividad a la CSE y a los pronunciamientos del CEDS sobre la misma. $^{82}$

Se ha alegado por los Tribunales nacionales que la CSE es una suerte de Directiva y que no se puede invocar directamente. Pero la CSE no impone sólo a los Estados legislar en uno u otro sentido lo que, junto a la falta de poder interponer reclamaciones colectivas en España, provoca que los particulares no puedan invocarla directamente, sino que

\footnotetext{
${ }^{80}$ GARCÍA GONZÁLEZ, G., "El sinuoso e inconcluso...", op. cit., p. 210; y JIMENA QUESADA, L. y SALCEDO BELTRÁN, C., "Desafíos para la...", op. cit., p. 279.

${ }^{81}$ GARCÍA GONZÁLEZ, G., "El sinuoso e inconcluso...", op. cit., p. 198; y NIVARD, C., "La justiciabilidad de...", op. cit., pp. 20-21, que habla de su falta de carácter de "self-executing", que deberia tener y no tiene: por un lado, el criterio subjetivo que supone que los Estados Partes deben haber tenido la intención de conceder tal efecto creando derechos subjetivos con destino a los individuos y no simples obligaciones interestatales. Y, por otro lado, el criterio objetivo que exige que la norma sea suficientemente precisa para no requerir medidas internas con el fin de completarlo. Al respecto, cita DUPUY P.M. / KERBRAT Y., Droit international public, Dalloz, 2012, 11 1 ed., p. 450.

${ }^{82}$ JIMENA QUESADA, L. "Las grandes líneas jurisprudenciales...", op. cit., pp. 21-22.
} 
gracias a los pronunciamientos del CEDS, reconoce una serie de derechos que no son meramente programáticos y que, en cuanto un Estado los ha ratificado, son directamente aplicables. $^{83}$

El primer pronunciamiento de un Tribunal aplicando directamente la CSE se produjo en el año 2013 en la Sentencia del Juzgado de lo Social 412/2013, de 19 de noviembre, en un asunto relacionado con el apoyo a los emprendedores regulado por el RDL 3/2012. Tras este pronunciamiento, muchos otros Tribunales inferiores, como pronunció el voto particular de la STSJ de Cataluña 4090/2015, de 22 de junio -exigiendo la aplicación directa de la CSE- vinieron haciéndose eco del control de convencionalidad seguido por los órganos jurisdiccionales catalanes. ${ }^{84}$ Pero si así han respondido los Jueces y Tribunales de primera y segunda instancia, nuestro Tribunal Supremo ha sido más reacio. El TS continúa inadmitiendo los recursos de casación en unificación de doctrina que utilizan las decisiones y conclusiones del CEDS para alegar la existencia de contradicción respecto a resoluciones derivadas de los órganos jurisdiccionales nacionales. ${ }^{85}$ Por su parte, el TC no ha seguido una línea unívoca en esta materia, creando cierta confusión al respecto. Así lo a reflejado en las SSTC 49/2015 y 95/2015, ${ }^{86}$ o la STC 119/2014 (frente al RDL 28/2012) donde se pueden ver opiniones discrepantes, aunque, como el TS, ha rechazado la aplicación directa de la CSE. ${ }^{87}$

A nivel europeo, en nuestros países vecinos, esta práctica está calando en los Tribunales de nuestro entorno. Así, cada vez más jueces admiten de controlar las disposiciones de la CSE, como demuestran los órganos jurisdiccionales franceses y belgas. Así, el Conseil d'Etat francés reconocía el efecto directo de los artículos 5 (Derecho sindical)25 y 24 (Derecho a protección en caso de despido)26 de la Carta social revisada; y el Conseil d'Etat belga aceptó la invocación de algunas disposiciones de la Carta social como el derecho a acciones colectivas, incluido el derecho de huelga,

\footnotetext{
${ }^{83}$ Así, por ejemplo, en la STSJ de Cataluña 4090/2015, de 22 de junio, concretamente en su voto particular, se argumentó la eficacia directa de la CSE.

${ }^{84}$ JIMENA QUESADA, L. "Las grandes líneas jurisprudenciales...", op. cit., pp. 23-24.

${ }^{85}$ GARCÍA GONZÁLEZ, G., "El sinuoso e inconcluso...", op. cit., pp. 213-214, con numerosas referencias jurisprudenciales.

${ }^{86}$ Recordamos aquí que el 7 de diciembre de 2012 el CEDS adoptó cinco Decisiones de fondo de resolución de las Reclamaciones $n^{\circ} 76$ a 80/2012, todas ellas contra Grecia y sus medidas de austeridad.

${ }^{87}$ NIVARD, C., "La justiciabilidad de...", op. cit., pp. 23-24, con referencia a SSJS de Barcelona ${ }^{\circ} 2$ de 19 de noviembre de 2013 ( $\mathrm{n}^{\circ}$ 421/2013), Tarragona $\mathrm{n}^{\circ} 1$ de 2 de abril de 2014 ( $\mathrm{n}^{\circ}$ 179/2014), Mataró $\mathrm{n}^{\circ} 1$ de 29 de abril de 2014 ( $\mathrm{n}^{\circ}$ 144/2014), Barcelona $\mathrm{n}^{\circ} 3$ de 5 de noviembre de 2014 ( $\mathrm{n}^{\circ}$ 352/2014), Barcelona $\mathrm{n}^{\circ} 19$ de 5 de noviembre de 2014 ( $\left.\mathrm{n}^{\circ} 352 / 2014\right)$, Toledo $\mathrm{n}^{\circ} 1$ de 27 de noviembre de $2014\left(\mathrm{n}^{\circ}\right.$ 536/2014), Las Palmas de Gran Canaria $\mathrm{n}^{\circ} 9$ y Fuerteventura ${ }^{\circ} 2$ de 31 de marzo de $2015\left(\mathrm{n}^{\circ} 705 / 2014\right.$ y $\mathrm{n}^{\circ}$ 58/2015), Toledo $\mathrm{n}^{\circ} 2$ de 9 de abril de 2015 ( $\mathrm{n}^{\circ}$ 202/2015), Las Palmas de Gran Canaria ${ }^{\circ} 1$ de 11 de mayo y 3 de junio de 2015 ( $n^{\circ} 74 / 2015$ y 816/2014). Sobre TS, Auto de 4 de noviembre de 2015, recurso no 926/2015; y sobre TC, STC 119/2014, de 16 de julio de 2014.
} 
garantizado al artículo $6{ }^{88}$ El origen de los problemas se debe no a la interpretación que realizan los jueces nacionales, sino al hecho de que en lugar de interpretar los órganos nacionales deberían tener en cuenta la interpretación que de dichos preceptos hace el CEDS. Si se tuviera en cuenta la labor del CEDS y los órganos nacionales se remitieran a la misma, la uniformidad de criterio respecto de determinados derechos sociales los haría más efectivos.

Somos conscientes de que este tipo de actuación por parte de los Tribunales implica el reconocimiento de los derechos sociales y el señalar al Poder legislativo que asuma unos derechos sociales con el contenido definido por el CEDS, lo que es evidentemente tiene sus implicaciones políticas y presupuestarias. No podemos olvidar, como ha dicho el TEDH, que los Estados tienen un amplio margen de apreciación para priorizar los gastos sociales, en tanto que los recursos disponibles de un Estado son limitados, ${ }^{89} \mathrm{y}$ que dejar en manos del Consejo de Europa, las obligaciones prestaciones de los Estados, situaría a éstos en una delicada situación. ${ }^{90}$ Pero no podemos olvidar tampoco la tan reclamada indivisibilidad de los derechos y de sus garantías, que no pueden ser sólo jurisdiccionales.

\section{El Defensor del Pueblo}

El Defensor del Pueblo tiene la misión esencial de proteger los derechos y libertades públicas recogidos en el Título I de nuestro texto constitucional. Así lo reconoce el artículo 54 CE, además del artículo 1 de la LO 3/1981 que regula y desarrolla dicha figura. Su independencia e imparcialidad le hacen el instrumento idóneo para proteger los derechos de los ciudadanos frente al abuso de los poderes públicos. ${ }^{91}$ No podemos olvidar que "es el único órgano del Estado dedicado en exclusiva a la garantía de los derechos fundamentales". 92

La actuación del Defensor del Pueblo no sólo a instancia de parte, sino también de oficio, le convierten en una pieza clave para la defensa de los derechos sociales, especialmente en épocas de crisis. Tal y como reflejara el propio Defensor del Pueblo

\footnotetext{
${ }^{88}$ NIVARD, C., "La justiciabilidad de...", op. cit., pp. 22-23, para quien es cuestionable que la misma disposición sea objeto de apreciación en función de quien la interprete, a pesar de apreciarse una evolución en la interpretación de la CSE. Vid. SALCEDO BELTRÁN, C., "La aplicabilidad directa de la Carta Social Europea por los órganos judiciales", Trabajo y Derecho, enero 2016, n ${ }^{\circ}$, pp. 27-52.

${ }^{89}$ Así, por ejemplo, vid. STEDH de 8 de julio de 2003, caso Sentges contra Holanda, en relación con la cobertura de asistencia sanitaria que le fue denegada a un menor que sufría una enfermedad degenerativa, utilizaba una silla de ruedas y había solicitado un ayuda para un brazo robotizado.

${ }^{90}$ CARMONA CUENCA, E., "Derechos sociales...", op. cit., p. 1221.

${ }^{91}$ Las prerrogativas del Defensor del Pueblo se recogen en los artículos 6 y 7 LODP.

${ }^{92}$ ESCOBAR ROCA, G., Nuevos derechos y garantías de los derechos, 2018, p. 181.
} 
español en su Informe anual de 2017, las consecuencias de la crisis económica tienen un impacto directo en los derechos sociales y en su realización efectiva, y es aquí cuando una institución como el Defensor del Pueblo debe ocuparse de que los poderes públicos garanticen un mínimo vital para todos los ciudadanos, con especial atención a los grupos vulnerables, evitando así un enquistamiento de situaciones de desigualdad. ${ }^{93}$

Así, por poner alguno de los múltiples ejemplos donde se puede ver que el Defensor del Pueblo puede ser el mejor aliado de la CSE y del papel del CEDS, recordamos aquí que en la presentación del Informe anual de 2018, en junio de 2019, el Defensor del Pueblo instó a los poderes públicos a implementar de manera "urgente" una política de vivienda que fomentara el alquiler social entre los grupos que más hubieran sufridos los efectos de la crisis económica, y lo hizo al hilo de recordar el Dictamen del CEDS de 2018 sobre los incumplimientos de España en materia de derechos sociales, del que ya hemos hablado, exigiendo a la Administración pública un análisis y actuación coordinada con el CEDS. ${ }^{94}$

El Defensor del Pueblo no debería centrarse sólo en la resolución de casos particulares, sino que en virtud de su competencia de iniciación de actuaciones de oficio debería hacer frente a problemas estructurales de nuestro Estado, tomando como referente, así lo creemos, la labor del CEDS en este terreno. ${ }^{95}$ Las funciones del Defensor del Pueblo han evolucionado y la globalización y los compromisos internacionales le deben convertir en un protector de los derechos sociales no sólo reconocidos en nuestro texto constitucional, sino de los reconocidos en textos y tratados internacionales, como es el caso de la CSE.

\footnotetext{
${ }^{93}$ Vid. Informe anual 2017. Actividades y actuaciones llevadas a cabo a lo largo del año 2017, de fecha 19 de marzo de 2018. Disponible on line: https://www.defensordelpueblo.es/informe-anual/informeanual-2017/. En la presentación del Informe el Defensor del Pueblo puso de manifiesto que la salida de la crisis económica puede representar una "oportunidad para revisar el funcionamiento de las política sociales", dado que, por desgracia, la desigualdad generada no se corrige ni reduce por sí sola requiriéndose de políticas sociales activas.

${ }^{94}$ Informe anual 2018. Actividades y actuaciones llevadas a cabo a lo largo del año 20178, de fecha 11 de junio de 2019. Disponible on line: https://www.defensordelpueblo.es/informe-anual/informe-anual2018/. Se recuerda aquí el caso de la familia con hijos menores que había sido desahuciada en 2013 y por lo que España fue sancionada en 2017.

${ }^{95}$ ESCOBAR ROCA, G., Nuevos derechos y garantías..., op. cit., p. 184.
} 


\section{A MODO DE CONCLUSIÓN}

Es evidente que la efectividad de los derechos sociales depende de la existencia de una clara voluntad política, pero "en el terreno político debe quedar claro que el coste de no respetar los derechos sociales es mayor que el de su respeto". ${ }^{96}$

En España, a falta de una ratificación de la CSE revisada y, especialmente, de su Protocolo de 1995 con la posibilidad de interponer reclamaciones colectivas, lo que pudiera evidenciar, aún más, la necesidad de su aplicación directa por nuestro Estado, no se puede dejar en manos de los Tribunales el aplicar o no directamente la CSE. La solución pasa por recordar la eficacia y vinculatoriedad del CEDS y por una clara labor por parte del Defensor del Pueblo de hacerlo valer ante las instituciones españolas, dadas sus funciones constitucionales de protección de los derechos y libertades públicas.

Es cierto, como ha recordado el TEDH, que en política social los Estados tienen un margen de apreciación, en tanto que los derechos sociales nacen vinculados a recursos y prestaciones limitadas. Pero no podemos olvidar, por otro lado, que de la misma forma que se protegen y garantizan derechos civiles y políticos, deben garantizarse los derechos sociales -como se deriva del reconocimiento internacional del principio de indivisibilidad de los derechos-, vinculados a la dignidad humana. ${ }^{97} \mathrm{Y}$ aquí, la labor del CEDS, más que la del propio TEDH, ha sido la de establecer un estándar mínimo de protección más favorable, ${ }^{98}$ y a ella deberíamos acogernos y no dejar su efectividad de la mano de los Tribunales nacionales -sin desmerecer la importante labor jurisprudencial en este terreno y sin dejar de dar gracias a que muchos de ellos garantizan los derechos sociales como lo haría el CEDS- 99

No podemos reducir la efectividad y garantía de los derechos sociales sólo a la sede jurisdiccional, ya sean Tribunales nacionales o vía reconocimiento del valor de los pronunciamientos del CEDS, sino que los poderes públicos tienen mucho que decir al respecto, en tanto que serán los que demuestren efectivamente, si los derechos sociales están siendo o no realizados. Y para controlar esta implementación y garantía, y que los derechos sociales no se limiten, especialmente en tiempos de crisis, está el Defensor del

\footnotetext{
96 JIMENA QUESADA, L., “El último bastión...”, op. cit., pp. 187-189; y JIMENA QUESADA, L., "Protection of refugees...", op. cit., p. 252.

${ }^{97}$ ESCOBAR ROCA, G., Nuevos derechos y garantías ..., op. cit., pp. 62-64.

${ }^{98}$ Así lo ha dicho en el asunto Koufakis contra Grecia, STEDH de 7 de mayo de 2017. En este sentido, vid. CANOSA USERA, R., "Carta Social Europea...”, op. cit., p. 160.

99 JIMENA QUESADA, L., "El constitucionalismo social y los Objetivos de Desarrollo Sostenible (ODS)", Lex social, vol. 9, n 1, 2019, pp. 42-43, quien habla del "papel subsidiario" de los órganos jurisdiccionales nacionales.
} 
Pueblo. El Defensor, dentro de sus funciones, no sólo debe garantizar que se cumplan los derechos sociales (lo que debería hacer, y ha hecho, tomando como referencia los pronunciamientos del CEDS), ${ }^{100}$ sino que debe exigir a los poderes públicos que lleven a cabo políticas públicas sociales activas, como ha venido señalando en sus últimos Informes anuales.

Por último, no podemos olvidar que los derechos sociales deben ser protegidos y a esa defensa van dirigidos también los objetivos de la Agenda 2030, de la que se ha dicho que "constituye una Agenda de Constitucionalismo Global de naturaleza básicamente social", cuyos objetivos representan "una especie de Pilar Universal de Derechos Sociales". ${ }^{101}$ Más allá de los pronunciamientos normativos existentes y de los correspondientes pronunciamientos jurisprudenciales, en septiembre de 2015, los líderes de los diferentes Gobiernos de todo el mundo, reunidos en la Asamblea General de la Organización de las Naciones Unidas (ONU) aprobaron la conocida Agenda 2030 donde recogieron los conocidos 17 Objetivos de Desarrollo Sostenible (ODS). Se evidencia en la Agenda que los derechos sociales representan un elemento de "redistribución de la riqueza, de realización de sociedades más igualitarias, expresión de la solidaridad social y (...) un medio capital para que las personas puedan gozar de una vida digna". ${ }^{102}$

Por todo ello, la respuesta debe venir de la mano de la importante labor que ha venido, y viene, desarrollando el CEDS. El dejar la protección de los derechos sociales sólo en

100 Esto demostraría que "el CEDS es el "último baluarte" del modelo europeo de Estado social frente a políticas comunitarias y estatales que lo estuvieran desmantelando"; y que no se pueden realizar restricciones de los derechos reconocidos en la CSE bajo el argumento de un interés público. Vid., Reclamaciones colectivas $n^{\circ}$ 65/2011 y 66/2011, de 23 de mayo de 2012, donde el CEDS ante normas nacionales que permitían despidos sin preaviso ni indemnización o que restringían las vacaciones anuales o la cobertura de la Seguridad social, deja claro que "La crisis económica no debe traducirse en una reducción de la protección de los derechos reconocidos por la Carta. Los Gobiernos deben por tanto adoptar todas las medidas necesarias para conseguir que esos derechos sean efectivamente garantizados en el momento en el que la necesidad de protección se hace sentir más (...)". Junto a dichas Decisiones, vid. también las Decisiones de 7 de diciembre de 2012 sobre las Reclamaciones n 76 a 80/2012 sobre la reducción de pensiones en Grecia. En las Conclusiones sobre España del CEDS, publicadas en enero de 2014, el CEDS señaló que excluir del sistema sanitario español a los inmigrantes que estuvieran en situación irregular en nuestro país (lo que se hizo por el RDL 16/2012, de 20 de abril, de medidas urgentes para garantizar la sostenibilidad del Sistema Nacional de Salud) contravenía la Carta Social Europea. Vid. JIMENA QUESADA, L., “El papel del Comité...”, op. cit., pp. 181-182 y 187-188.

${ }^{101}$ La Agenda 2030 fue adoptada por la Asamblea General de las Naciones Unidas el 25 de septiembre de 2015. Sobre los Objetivos de la Agenda, vid. https://www.un.org/sustainabledevelopment/es/2015/09/laasamblea-general-adopta-la-agenda-2030-para-el-desarrollo-sostenible/. Sobre los Objetivos y su vinculación con la Carta, vid. JIMENA QUESADA, L., "El constitucionalismo social...”, op. cit.

102 Vid. TAMER, S.V., La garantía judicial..., op. cit., pp. 139-140; con referencia a MARTÍNEZ DE PISÓN, J.M". "La efectividad de los derechos sociales: de las necesidades básicas al desarrollo humano", en GARCÍA INDA, A. / MARTÍNEZ DE PISÓN, J.Ma . (Coords.), Derechos fundamentales, movimientos sociales y participación, Dykinson, Madrid, 2003, p. 132. 
manos del TEDH cuando éste no es un órgano especializado en derechos sociales provoca un "déficit garantista" de los mismos: la cuestión no es, o no debería ser, su justiciabilidad, sino su efectividad, la forma de hacer efectivos los pronunciamientos jurisprudenciales. El CEDS está más preparado para ello que el TEDH, ${ }^{103}$ que salvo contadas excepciones, tutela de manera indirecta los derechos sociales, ofreciendo sólo una garantía de contenidos mínimos y haciendo primar el margen de apreciación de los Estados, que no se muestran receptivos ni al principio de proporcionalidad ni al de las obligaciones positivas. ${ }^{104}$ En cambio, el CEDS ha dejado patente -como en el caso de las medidas anticrisis- que debe primar la protección social de los individuos frente al margen de apreciación de los Estados en este terreno. Los Tribunales nacionales, especialmente los de los órdenes jurídicos inferiores están haciendo una excelente labor de aplicación directa de la CSE entendida como un Tratado directamente vinculante para nuestro Estado.

Pero la protección social sólo se puede hacer efectiva con medidas concretas, y es aquí donde el Defensor del Pueblo puede evidenciar la asignatura pendiente de España en este terreno: España debe ratificar la CSE revisada y asumir la garantía de las reclamaciones colectivas. Los poderes públicos nacionales deben ser responsables y coherentes con los compromisos internacionales sobre derechos humanos suscritos, ${ }^{105} \mathrm{y}$ con la aplicación directa igualmente del principio de indivisibilidad de los derechos, doctrina "consolidada y no contradicha". ${ }^{06}$

\footnotetext{
103 JIMENA QUESADA, L., "El último bastión...", op. cit., p. 175, quien considera que debido a la dificultad de ejecución de las Sentencias del TEDH sobre esta materia, más que de justiciabilidad es preferible hablar de efectividad, independientemente del tipo de derecho frente al que nos encontremos, civiles y políticos o sociales y económicos, citando como ejemplo la falta de eficacia del asunto Marckx contra Bélgica, de 13 de junio de 1979, donde el Estado belga tardó unos once años en modificar su legislación civil con el fin de equiparar a los hijos habidos fuera y dentro del matrimonio. Al respecto, vid. también, BELORGEY, J.M., "La Carta Social...", op. cit., p. 358; y PÉREZ ALBERDI, M.R., "La protección de los derechos sociales en la jurisprudencia del Tribunal Europeo de Derechos Humanos", en TEROL BECERRA, M. / JIMENA QUESADA, L. (Dirs.), Tratado sobre protección de derechos sociales, Tirant lo Blanch, Valencia, 2014, pp. 319-332.

${ }^{104}$ GARCÍA VITORIA, I., "La jurisprudencia del...", op. cit., p. 116.

105 JIMENA QUESADA, L., "El papel del Comité...”, op. cit., pp. 191-192, quien recuerda la necesidad de respetar el mandato del art. 10.2 CE y quien recuerda con tristeza que nuestros Tribunales ignoraron "una vez más" el canon europeo establecido por el CEDS, y cita la STC 139/2016. En esta misma línea, BELORGEY, J.M., "La Carta Social...", op. cit., p. 359, señala que "El Estado es, por ende, responsable de los compromisos contraídos en el marco de la Carta".

${ }^{106}$ ESCOBAR ROCA, G., Nuevos derechos y garantías..., op. cit., p. 63, quien acertadamente acude al art. 38 del Estatuto del Tribunal Internacional de Justicia, que al considerarlo un principio jurídico, lo dota de fuerza vinculante también a nivel nacional.
} 


\section{BIBLIOGRAFIA}

BELORGEY, J.M., "La Carta Social Europea del Consejo de Europa y su órgano de control: el Comité europeo de Derechos Sociales", Revista de Derecho Político UNED, n 70,2007 , pp. 349-377.

BINDER, C. / STEINER, E., "The European Court of Human Rights and Social Rights", en BINDER, C. (Ed.), Social Rights in the Case Law of Regional Human Rights Monitoring Institutions, Intersentia, Antwerp, 2016, pp. 52-59.

BURGOS ADURIZ, A. "La protección del contenido esencial de la libertad sindical en la Unión Europea ¿cómo afectaría esta situación a la futura adhesión de la Unión Europea al Convenio Europeo de Derechos Humanos? Contradicciones con la jurisprudencia del Tribunal Europeo de Derechos Humanos", Revista de Estudios Europeos, ${ }^{\circ}$ 71, 2018, pp. 259-272.

CANOSA USERA, R., "Carta Social Europea y Comité Europeo de Derechos Sociales", en MASALA, P. (Ed.), La Europa social: alcances, retrocesos y desafíos para la construcción de un espacio jurídico de solidaridad, CEPC, Madrid, 2018, pp. 143-172.

CARMONA CONTRERAS, A., "La afirmación de derechos en el espacio social europeo: luces y sombras de un proceso (todavía) en construcción", en MASALA, P. (Ed.), La Europa social: alcances, retrocesos y desafíos para la construcción de un espacio jurídico de solidaridad, CEPC, Madrid, 2018, pp. 53-79.

CARMONA CUENCA, E., "Derechos sociales de prestación y obligaciones positivas del Estado en la jurisprudencia del Tribunal Europeo de Derechos Humanos", Revista de Derecho Político, n 100, 2017, pp. 1209-1238.

CARRILLO SALCEDO, J.A., "Protección de los derechos humanos en el Consejo de Europa: hacia la superación de la dualidad entre derechos civiles y políticos y derechos económicos y sociales", Revista de Instituciones Europeas, Vol. 18, nº 2, 1991, pp. 431454.

DÍEZ PICAZO, L.M., Sistema de derechos fundamentales, $2^{\mathrm{a}}$ ed., Aranzadi, Navarra, 2005.

ESCOBAR ROCA, G., "Indivisibilidad y derechos sociales. De la Declaración Universal a la Constitución”, Lex Social. Revista de los Derechos Sociales, n 2, 2012, pp. 47-61.

ESCOBAR ROCA, G., Nuevos derechos y garantías de los derechos, Marcial Pons, Madrid, 2018. 
FERNÁNDEZ BURGUEÑO, B., "El trabajo forzado, la servidumbre y la esclavitud en Europa atendiendo a los sectores productivos: análisis crítico del alcance de la jurisprudencia del artículo 4 del Convenio Europeo de Derechos Humanos", Universitas, $\mathrm{n}^{\circ}$ 25, 2017, pp. 90-138.

GARCÍA GONZÁLEZ, G., "El sinuoso e inconcluso proceso de adhesión de España a la Carta Social Europea: resistencias, imperfecciones y retos de futuro", Lex Social, Vol. 9, no 1, 2019, pp. 193-219.

GARCÍA ROCA, J., El margen de apreciación en la interpretación del Convenio Europeo de Derechos Humanos. Soberanía e integración, Civitas, Madrid, 2010.

GARCÍA ROCA, J., "La transformación del Convenio Europeo de Derechos Humanos", Revista General de Derecho Constitucional, n 28, 2018.

GARCÍA VITORIA, I., "La jurisprudencia del Tribunal Europeo de Derechos Humanos sobre los derechos sociales", en MASALA, P. (Ed.), La Europa social: alcances, retrocesos y desafíos para la construcción de un espacio jurídico de solidaridad, CEPC, Madrid, 2018, pp. 115-142.

GIUBBONI, S., "European citizenship and social Rights in times of crisis", German Law Journal, vol. 15, n 5, 2014, pp. 935-964.

JIMENA QUESADA, L. / TOMÁS MALLÉN, B.S, "Hacia un estándar europeo común de igualdad: la contribución del Comité Europeo de Derechos Sociales", Revista de Derecho Político UNED, $\mathrm{n}^{\circ}$ 68, 2007, pp. 339- 359.

JIMENA QUESADA, L., "El último bastión en la defensa de los derechos sociales: la Carta Social Europea", RJUAM, n 29, 2014, pp. 171-189.

JIMENA QUESADA, L., "Protection of refugees and other vulnerable persons under the European Social Charter", Revista de Derecho Politico UNED, n 92, 2015, pp. 245272.

JIMENA QUESADA, "Las grandes líneas jurisprudenciales del Comité Europeo de Derechos Sociales: tributo a Jean Michel Belorgey", Lex social, Vol. 7, nº 1, 2017, pp. $1-25$.

JIMENA QUESADA, L., "El papel del Comité Europeo de Derechos Sociales en el contexto de la crisis económica", en MASALA, P. (Ed.), La Europa social: alcances, retrocesos y desafíos para la construcción de un espacio jurídico de solidaridad, CEPC, Madrid, 2018, pp. 173-208.

JIMENA QUESADA, L., "El constitucionalismo social y los Objetivos de Desarrollo Sostenible (ODS)", Lex social, vol. 9, n 1, 2019, pp. 13-45. 
JIMÉNEZ GARCÍA, F., "La Carta Social Europea (Revisada): Entre el desconocimiento y su revitalización como instrumento de coordinación de las políticas sociales europeas", Revista Electrónica de Estudios Internacionales, n 17, 2009, pp. 79-124.

LAPORTA, F., "Los derechos sociales y su protección jurídica: introducción al problema", en BETEGÓN, J. (Coord.), Constitución y derechos fundamentales, CEPC, Madrid, 2004.

LOPEZ AHUMADA, J.E., "Trabajo decente y globalización en Latinoamérica: una alternativa a la desigualdad laboral y social", Documentos de Trabajo IELAT, $\mathrm{n}^{\circ}$ 98, 2017.

LÓPEZ GUERRA, L., "La protección de los derechos económicos y sociales en el Convenio Europeo de Derechos Humanos", en TEROL BECERRA, M. / JIMENA QUESADA, L. (Dirs.), Tratado sobre protección de derechos sociales, Tirant lo Blanch, Valencia, 2014, pp. 297-317.

LÓPEZ GUERRA, L., "Crisis económica y derechos humanos. Una nota de jurisprudencia”, en Teoría y Realidad Constitucional, nº 36, 2015, pp. 399-414.

LOUSADA AROCHENA, J.F., "Normativa internacional contra la explotación humana y laboral en el trabajo doméstico: la ONU y la OIT", Lan Harremanak, no 39, 2018, pp. 152-187.

MARTÍNEZ DE PISÓN, J.M"., "La efectividad de los derechos sociales: de las necesidades básicas al desarrollo humano", en GARCÍA INDA, A. / MARTÍNEZ DE PISÓN, J.M ${ }^{\mathrm{a}}$. (Coords.), Derechos fundamentales, movimientos sociales $y$ participación, Dykinson, Madrid, 2003, pp. 131-156.

MORTE GÓMEZ, C. / SALINAS ALCEGA, S., "Los derechos económicos y sociales en la jurisprudencia del Tribunal Europeo de Derechos Humanos", en EMBID IRUJO, A. (Dir.), Derechos económicos y sociales, Iustel, Madrid, 2009, pp. 359-412.

NIVARD, C., "La justiciabilidad de los derechos sociales en el Consejo de Europa", Lex Social, Vol. 6, n 2, 2016, pp. 12-33.

PÉREZ ALBERDI, M.R., "La jurisprudencia social del Tribunal Europeo de Derechos Humanos", Lex Social. Revista de los Derechos Sociales, n 1, 2011, pp. 93-105.

PÉREZ ALBERDI, M.R., "La protección de los derechos sociales en la jurisprudencia del Tribunal Europeo de Derechos Humanos", en TEROL BECERRA, M. / JIMENA QUESADA, L. (Dirs.), Tratado sobre protección de derechos sociales, Tirant lo Blanch, Valencia, 2014, pp. 319-332. 
SANTOLAYA MACHETTI, P. / DÍAZ RICCI, S. "Los derechos económicos, sociales y culturales y la protección de grupos vulnerables", en GARCÍA ROCA, J. I FERNÁNDEZ, P.A. / SANTOLAYA, P. / CANOSA, R. (Eds.), El diálogo entre los Sistemas Europeo y Americano de Derechos Humanos, Civitas, Navarra, 2012, pp. 249286.

SALCEDO BELTRÁN, C., "Derechos sociales y su garantía: la ineludible aprehensión, disposición e implementación de Carta Social Europea (Constitución Social de Europa)", Revista de Derecho Social, no 83, 2018, pp. 45-74.

SALCEDO BELTRÁN, C., "Conclusiones XXI-3 (2018) del Comité Europeo de Derechos Sociales: Evidencias de la "indiferencia" y "resistencia" a la Carta Social Europea", en Crónica Europea, n 5, 2019, pp. 541-552.

TAMER, S.V., La garantía judicial de los derechos sociales y su legitimidad democrática, Ratio Legis, Salamanca, 2018.

TEIXEIRA ALVES, L., El cumplimiento de la Carta Social Europea en materia de salarios: un estudio comparado de los ordenamientos laborales portugués, español e italiano, Barcelona, Atelier, 2014, pp. 15 y ss. 